Article

\title{
Economic Evaluation of Actively Consuming Wind Power for an Integrated Energy System Based on Game Theory
}

\author{
Xiaojuan Han ${ }^{1, *}$, Feng Wang ${ }^{1}$, Chunguang Tian ${ }^{2}$, Kai Xue ${ }^{3}$ and Junfeng Zhang ${ }^{3}$ \\ 1 School of Control and Computer Engineering, North China Electric Power University, \\ Beijing 102206, China; 18810994418@163.com \\ 2 Electrical Power Research Institute of Jilin Electric Power Corporation, Changchun 130021, China; \\ jlcctiancg@163.com \\ 3 Jilin Provincial Electric Power Training Center, Changchun 130021, China; xkeller@163.com (K.X.); \\ zjf0365138@126.com (J.Z.) \\ * Correspondence: wmhxj@163.com; Tel.: +86-130-0196-8881
}

Received: 20 March 2018; Accepted: 14 May 2018; Published: 6 June 2018

\begin{abstract}
Facing the growing problem of the curtailed wind during winter heating periods in the north of China, a flexible control method of wind power heating using the integrated energy system to consume the curtailed wind is proposed. Energy storage technology is introduced to coordinate regenerative electric boilers to match the fast fluctuation of wind power. The consuming model of the curtailed wind for the integrated energy system is established under three models through the study of the consumption mechanisms for the curtailed wind. The "wind power-energy storage system" and "wind power-regenerative electric boiler" are regarded as the game's participants, and the maximum daily benefit of the system is regarded as the objective function, an economic evaluation model of the integrated energy system to consume the curtailed wind based on game theory is established. For comparative analysis, the model is respectively solved by particle swarm optimization (PSO) and the firefly algorithm (FA). The effectiveness of the model is verified by the actual operation data of a wind power heating demonstration project in China. The simulation results show that the most economy benefits of the overall system can be obtained by using energy storage systems to coordinate regenerative electric boilers, which provides a theoretical basis for the consumption of the curtailed wind.
\end{abstract}

Keywords: energy storage system; regenerative electric boiler; the curtailed wind; game theory; economic evaluation

\section{Introduction}

As an inexhaustible source of clean energy, wind energy has become the most mature, largest, and widely used renewable energy power generation technology in the world. By the end of 2016, the global installed capacity of wind power had reached $486.749 \mathrm{GW}$. China has an accumulation of $168.69 \mathrm{GW}$, accounting for $34.7 \%$ of the total in the world [1]. With the increase of the installed capacity of wind power, the contradiction of the supply and demand between source and load in Northeast, Northwest, and North China has been aggravated. For the lack of receiving capacity, the mismatch between the construction periods of wind farms and the instability of wind power and other characteristics, the wind turbines in some wind farms have been suspended [2]. According to the Energy Bureau's statistics on the amount of the curtailed wind, the electricity curtailed by wind farms reached 33,900 GWh in 2015, with an increase of 21,300 GWh from 2014 and an average curtailed rate 
of 15\% [3]. The data of the curtailed wind from 2011 to 2015 are shown in Table 1, and the statistics on the data of the serious curtailed wind in provinces are given in Table 2.

Table 1. The data of the curtailed wind from 2011 to 2015.

\begin{tabular}{ccccc}
\hline Year & $\begin{array}{c}\text { Electricity of the } \\
\text { Curtailed Winds (GWh) }\end{array}$ & $\begin{array}{c}\text { The Average } \\
\text { Curtailed-Wind Rate (\%) }\end{array}$ & $\begin{array}{c}\text { Electricity Loss } \\
\text { (Billion \$) }\end{array}$ & $\begin{array}{c}\text { Converted to Raw } \\
\text { Coal (Million Tons) }\end{array}$ \\
\hline 2011 & 123,000 & $16.23 \%$ & 1.02 & 56.65 \\
2012 & 208,000 & $17.12 \%$ & 1.72 & 94.74 \\
2013 & 162,000 & $10.74 \%$ & 1.35 & 72.94 \\
2014 & 126,000 & $8.00 \%$ & 1.05 & 56.62 \\
2015 & 339,000 & $15.00 \%$ & 2.82 & 152.34 \\
Total & 959,000 & $13.00 \%$ & 7.97 & 433.30 \\
\hline
\end{tabular}

Table 2. Statistics on the data of the serious curtailed wind in provinces.

\begin{tabular}{ccc}
\hline Province & The Curtailed Electricity (GWh) & The Rate of the Curtailed Winds (\%) \\
\hline Inner Mongolia & 91,000 & $18 \%$ \\
Gansu & 82,000 & $39 \%$ \\
Xinjiang & 71,000 & $32 \%$ \\
Jilin & 27,000 & $32 \%$ \\
\hline
\end{tabular}

The emergence of large-scale curtailed wind not only seriously affects the efficiency of renewable energy power generation enterprises, but is also a serious waste of clean energy. Hence, how to solve the curtailed wind has become a key issue for the further development of wind power [4,5].

At present, the main measures to consume the curtailed wind are as follows [6]: (1) Build large-capacity and large-scale transmission lines between wind resource areas and load areas to enhance the power transmitting capacity among different areas. However, the construction period is long and the cost is high; (2) The establishment of a sound monitoring and forecasting mechanism of wind power is a prerequisite for a large number of the consumption of the curtailed wind. Due to the intermittent and random natures of wind power, the existing forecasting methods cannot accurately predict the output power; (3) The peak capability of wind power cooperating with other flexible power sources such as pumped storage, energy storage power stations, gas power stations, and regenerative electric boilers can provide a solid guarantee to improve the consumption of the curtailed wind, called as an integrated energy system.

To enhance the ability of the wind power consumption, a large number of experts and scholars have done a great deal of work. The complementary of a variety of power sources including thermal power, wind power, hydropower, photovoltaic, pumped storage and electric boiler is used to reduce the proportional of the curtailed wind $[7,8]$. During the winter heating period, the combined heat and power (CHP) is the main heating means. Since the heating unit is running on "ordering power by heat", the capacity of the system for peak shaving is seriously insufficient, and it cannot meet the requirements of large-scale wind power and photovoltaic generation [9]. Pumped storage, as one of the most economical and reliable means to consume the curtailed wind, plays a role of transferring wind energy in time and can mitigate the impact of wind power connected to the grid. A pumped storage power station is used to store the curtailed wind at night in the form of water energy, and deliver them to the grid when the load is in peak periods in the daytime, which has been widely used in many countries and regions. However, its construction period is too long [10-12]. Electric boilers can directly consume the curtailed wind for heating in low load periods to mitigate the heat pressure of the CHP units. Due to the heating demands in the north of China, there are a large number of the $\mathrm{CHP}$ units in the grid, and the difference between the peak and valley load is large. Researchers have not only limited in the view of the power system, but from the perspective of electricity and heat, heat storage technology is used to improve the consumption capacity of renewable energy $[13,14]$. 
Today, regenerative electric boilers become an effective way to consume the curtailed wind as one of the heat storage technologies.

At present, the research on wind power heating system using regenerative electric boilers mainly focuses on the aspects of optimal scheduling, capacity configuration and economic evaluation. In [15], the economic value of heat pumps combined electric boilers was assessed by a novel operational strategy with two-stage stochastic programming to simulate their day-to-day market performance. The main parameters affecting the profitability of heat pumps and electric boilers were analyzed, an assessment basis for investors before investing was provided. In [16], the development prospects of regenerative electric boilers, technical and economic analysis was carried out, the investment recovery period was less than 10 years. Achieving an optimum electric boiler configuration is important for power grid security where a relatively high wind power capacity and CHP units are installed. In [17], an optimum electric boiler capacity configuration model that maximizes comprehensive social benefits for a regional power grid was established based on various constraint conditions, such as the heat-power balance, with the objective of maximizing the associated social benefits. In [18], according to the analysis of the coupling relationship between power system and thermal system, the electric and heat supply and demand curves of the time shift and optimal matching are realized to establish a heat storage scheduling model. The feasibility of using heat storage system to improve the consumption capacity of the curtailed wind was verified by the actual operating data.

Two demonstration projects of wind power heating combined regenerative electric boilers were established in Jilin Province in 2012 and 2014, and another project was established in Western Inner Mongolia in 2013, respectively, with an installed capacity of $30 \mathrm{MW}$. After about two years of the actual operation, the electrode rods of regenerative electric boilers are subject to the constraints of the speed, depth and frequency, which can only be one-way adjusted, so it is difficult to match the rapidly fluctuating wind power and cannot consume the curtailed wind completely. Thus, using regenerative electric boilers to realize wind power consumption has problems of poor controllability and difficult regulation during operation, resulting in poor adaptability between wind power output and regenerative electric boilers. Due to the fast and bidirectional regulation of energy storage technology, it is often used to smooth the fluctuation of output power of renewable energy [19]. Therefore, the utilization of energy storage systems provides a new idea for the local consumption of the curtailed wind by improving the regulation performance of regenerative electric boilers [20].

In this paper, the heat-supply mechanism using energy storage system to coordinate regenerative electric boilers is studied, an active consumption method of the curtailed wind based on the integrated energy system is proposed. Considering the factors of the curtailment wind, the scale of energy storage systems and the operating conditions of regenerative electric boilers, a model of the integrated energy system including wind power, electric boiler and energy storage is established. Under the two operating conditions of the rated power and tracking wind power of regenerative electric boilers, the effects of the consumed amount and tracked on wind power before and after adding the energy storage system are analyzed. Taking "wind power-energy storage system" and "wind power-regenerative electric boiler" as participants in the game, considering various factors, such as energy storage system, regenerative electric boiler, wind farm, heating plant, cost and other factors, an economic evaluation model of the wind power consumption for the integrated energy system based on game theory is established. As the frequently adjustment of regenerative electric boilers will lead the reduction of the service life, the penalty factor related to the adjusting numbers of regenerative electric boilers is introduced in the model, the adjusting numbers can be reduced by the energy storage system. The PSO and FA algorithms are, respectively, used to solve the model for comparative analysis. Through the test of the actual operation data of demonstration project in China, the simulation results verified that the wind power consumption method using the energy storage to coordinate regenerative electric boilers has greater economic benefits. It provides a theoretical basis for wind power consumption using the integrated energy system. 


\section{The Operating Mechanism of Wind Power Heating Using Energy Storage System to Coordinate Regenerative Electric Boilers}

\subsection{The Operating Mechanism of Wind Power Heating Based on Regenerative Electric Boilers}

Generally, the grid needs to reserve a certain amount of additional regulation capacity to cope with the fluctuations of wind power output. However, during some periods, especially the load is in the low-valley period during the whole winter heating, the space of the grid to consume the curtailed wind is reduced, resulting in the large-scale wind power to be curtailed. The predicted monthly power generation and actual generation of a wind farm in China in 2015 are shown in Figure 1.

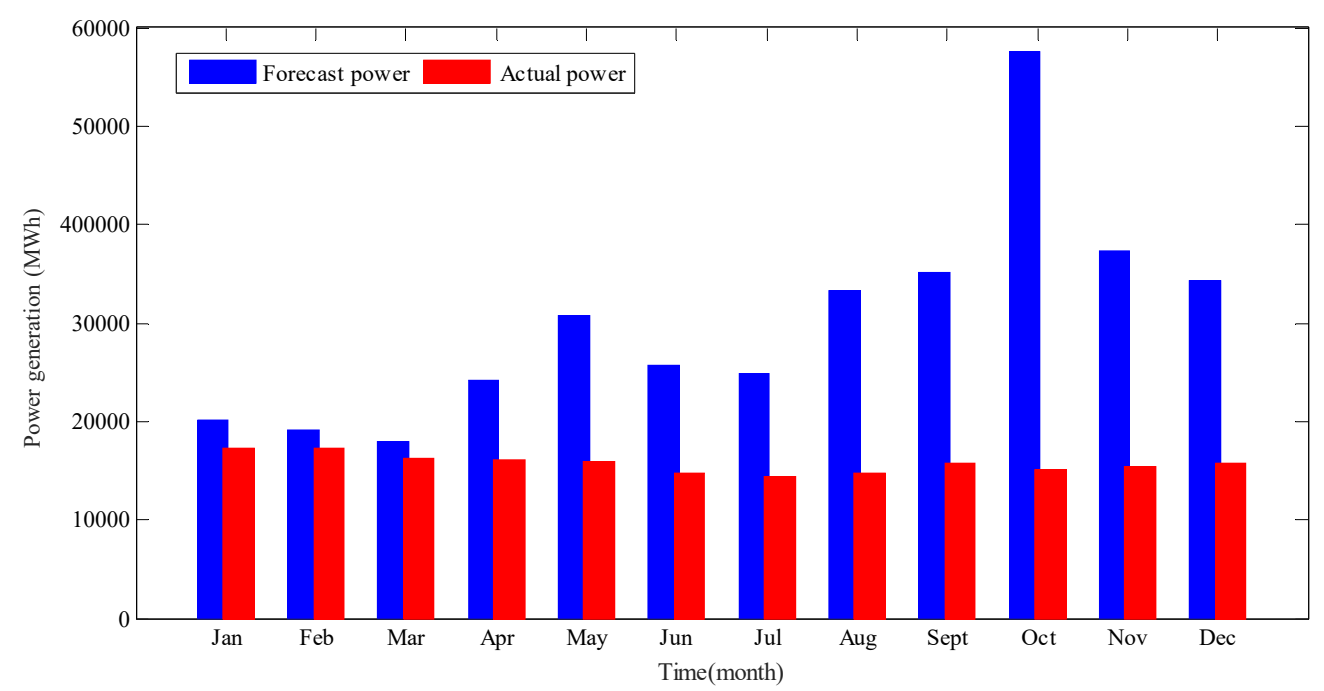

Figure 1. The monthly forecasting and actual power generation of a wind farm in China in 2015.

It can be seen from Figure 1 that the heating period in China is in good agreement with a large amount of wind resources, and the curtailed wind is obviously higher than other periods. Therefore, the wind power heating through regenerative electric boilers can maximize the utilization of high-quality wind resources to reach the purpose of reducing the curtailed wind.

A regenerative electric boiler [21] consists an electrode boiler and a regenerator. It is a new type of electric heating device with high safety performance, high-energy efficiency, and low-environmental pollution. The wind power heating mechanism using regenerative electric boilers to consume the curtailed wind is that regenerative electric boilers are regarded as a heat source instead of coal-fired boilers. At the same time it can be seen as a controllable load, which converts the wind power in the valley load period of the grid into heat energy, part of which is directly used for heating the residents, and the other part is stored for heating during the peak load period at the daytime. As the heating area is generally far away from the wind farm, the new route will increase the investment cost of wind farms if the wind power is used to directly power the regenerative electric boilers. Therefore, the non-straight power supply model is produced, that is, the electricity generated by the wind farm is sent to the grid, and regenerative electric boilers purchase the electricity from the grid to the heating system. Regenerative electric boilers run at constant power in the valley load periods during the night, which is supplemented by the grid to ensure the safe and stable operation of regenerative electric boilers when the wind farm provides insufficient power. Some of the heat generated during the night is sent directly to the heating company for the residents and the other part is stored in the heat storage tank, when the daytime peak load occurs, the heat storage tank begins to release heat. It is a very effective approach to fully enhance the capacity of wind power consumption during the valley load period of the grid and increase the load rate of the grid. The schematic diagram of the wind power heating based on regenerative electric boilers is shown in Figure 2. 


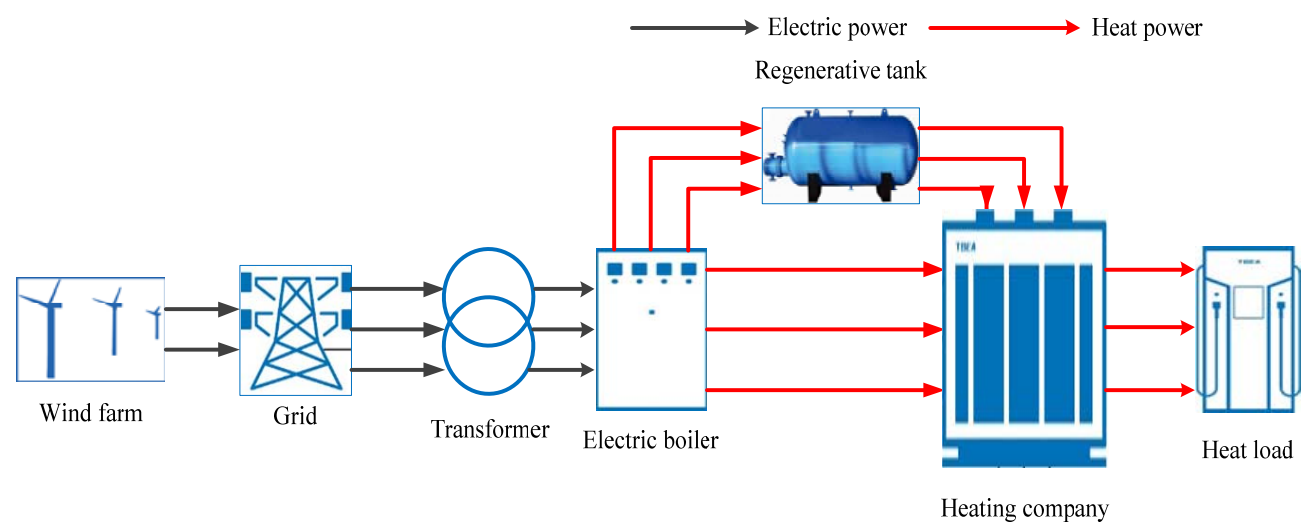

Figure 2. Schematic diagram of the wind power heating based on regenerative electric boilers.

For a wind farm, a large number of the curtailed wind is generated for the insufficient consumptive ability of the grid [22], and the curtailed wind power $P_{w}$ is defined as:

$$
P_{w}(t)=P_{\text {pre }}(t)-P_{S}(t)
$$

where $P_{\text {pre }}(t)$ is the forecasting wind power; $P_{S}(t)$ is the actual wind power.

The operating power of regenerative electric boilers $P_{b}$ needs to meet the following constraints:

$$
P_{b}^{\min } \leq P_{b}(t) \leq P_{b}^{\max }
$$

where $P_{b}(t)$ is the actual operating power of regenerative electric boilers at the moment $t . P_{b}^{\min }$ and $P_{b}^{\max }$ are the lower and upper limits of the operating power.

The daily electricity consumption $Q_{b}$ of regenerative electric boilers is calculated by Equation (3).

$$
Q_{b}=\int_{t_{1}}^{t_{2}} P_{t}(t) d t
$$

where $t_{1}$ and $t_{2}$ are, respectively, the start and stop time of regenerative electric boilers.

The amount of the curtailed wind absorbed by regenerative electric boilers at moment $t$ is calculated by Equation (4):

$$
E_{b}(t)=\left\{\begin{array}{l}
P_{w}(t), 0 \leq P_{w}(t) \leq P_{b}(t) \\
P_{b}(t), 0 \leq P_{b}(t) \leq P_{w}(t)
\end{array}\right.
$$

The operating power of regenerative electric boilers $P_{b}(t)$ needs to meet the following constraints:

$$
\left\{\begin{array}{l}
P(t)-P(t-1) \leq P_{b, \text { start }} \\
P(t-1)-P(t) \leq P_{b, \text { stop }}
\end{array}\right.
$$

It can be seen that when the actual operating power of regenerative electric boilers is greater than the curtailed wind, the curtailed wind is completely consumed. When the actual operating power of regenerative electric boilers is smaller than the curtailed wind, the curtailed wind still exists. The consumption of the curtailed wind a day is calculated by Equation (6):

$$
E_{w}=\int_{t_{0}}^{t_{d}} E_{b}(t) d t
$$

where $t_{0}$ and $t_{d}$ are the start and end of a day, respectively.

It can be seen from Equations (1)-(6) that the wind power heating based on regenerative electric boilers can not only absorb the curtailed wind to a certain extent, but can also reduce the reliance on 
thermal power units, and provide the heating for the residents, which has considerable environmental and economic benefits.

2.2. Wind Power Heating Mechanism Using Energy Storage System to Coordinate Regenerative Electric Boilers to Consume the Curtailed Wind

Although the wind power heating based on regenerative electric boilers can consume a certain amount of curtailed wind with good economic and environmental benefits, the operating power of regenerative electric boilers is adjusted by electrode rods, which can only be single-direction adjusted and limited by the speed, depth, frequency, and many other factors, it is difficult to match rapid fluctuations and randomness of the wind power. However, the energy storage technology has the characteristics of bidirectional regulation and time shift of the energy, it is used to enhance the scale and rapidity and flexibility of two-way adjustment of regenerative electric boilers in order to match the inherent output characteristics of wind power, which can effectively improve the imbalances between the "source" and "load" [23,24]. The schematic diagram of the wind power heating using energy storage system to coordinate regenerative electric boilers is shown in Figure 3.

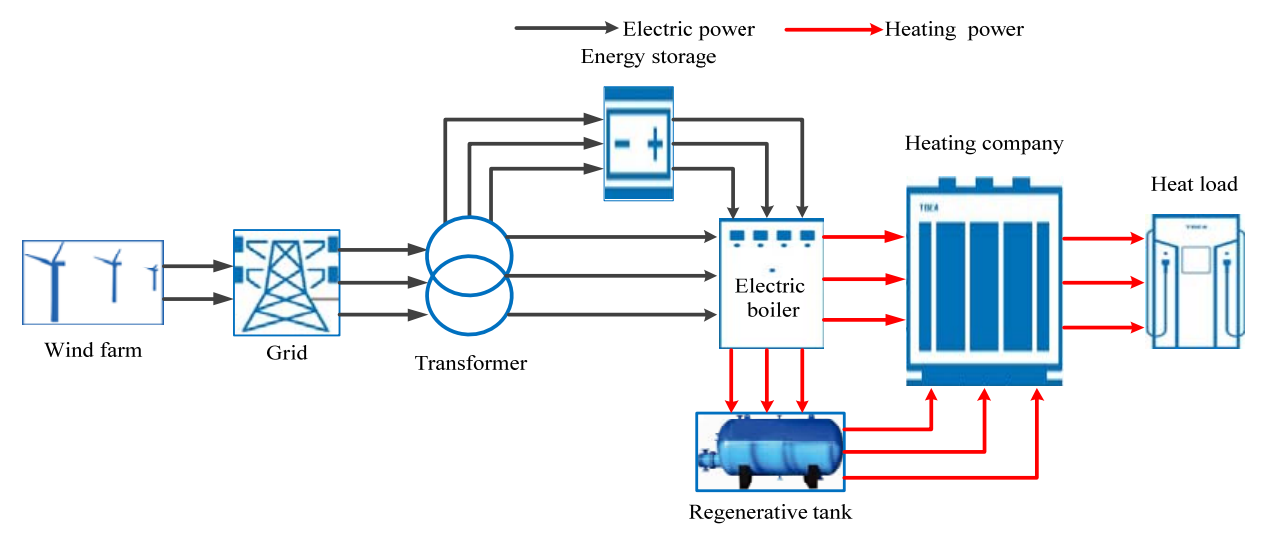

Figure 3. Schematic diagram of the wind power heating mechanism using energy storage system to coordinate regenerative electric boilers.

The energy storage system is configured on the load side, that is, located to the side of the regenerative electric boilers, the charging and discharging power $P_{e}(t)$ of the system satisfies the following constraints:

$$
\left|P_{e}(t)\right| \leq P_{e}^{\max }
$$

During the operation of the system, the state of charge $S O C(t)$ and the state transition of the energy storage system satisfy the following constraints:

$$
\begin{gathered}
\operatorname{SOC}_{\min } \leq S O C(t) \leq S O C_{\max } \\
\operatorname{SOC}(t)=(1-\tau) S O C(t-1)-\frac{P_{e}(t) \eta \Delta t}{E_{e}^{\max }} \\
E_{e}(t)=(1-\tau) E_{e}(t-1)-P_{e}(t) \eta \Delta t \\
\eta=\left\{\begin{array}{l}
\eta_{\text {charge }}, P_{e}(t) \leq 0 \\
\frac{1}{\eta_{\text {discharge }}}, P_{e}(t) \geq 0
\end{array}\right.
\end{gathered}
$$

where $\eta_{\text {charge}}, \eta_{\text {discharge }}$ are, respectively, the charging and discharging efficiency of the energy storage system.

The energy storage system is used to make the operating power of the regenerative electric boilers as much as possible track the curtailed wind so as to maximize the consumption of the curtailed wind 
and reduce the capacity configuration of the energy storage system. Thus, the daily heating production of the system needs to meet the minimum daily demands of the residents:

$$
Q_{b} \geq Q_{h o t}
$$

where $Q_{h o t}$ is the required minimum daily heating of the residents.

The charging and discharging power of the energy storage system $P_{e}(t)$ is calculated by Equation (10):

$$
P_{e}(t)=P_{w}(t)-P_{b}(t)
$$

Before the start operation of the regenerative electric boilers, the energy storage system has been fully charged by the curtailed wind, namely:

$$
\operatorname{SOC}\left(t_{0}\right)=S O C_{\max }
$$

Since the actual operating power of the regenerative electric boilers is regulated by the electrode rods, the electrode rods may have some mechanical damages during their regulation and greatly affect the service life. Thus, a restriction on the adjusting number $l$ is introduced. Similarly, the amount of the charging or discharging of the energy storage system also affects its service life. Therefore, the number of charging and discharging a day $n$ is also constrained as follows:

$$
\left\{\begin{array}{l}
l \leq a \\
n \leq b
\end{array}\right.
$$

where $a, b$ are constants.

It can be seen from Equations (7) to (11) when the operating power of the regenerative electric boilers is running under the mode of tracking the curtailed wind, it can consume more curtailed wind. After the energy storage system is added to the wind power heating system, it will track the curtailed wind more timely and accurately, improving the imbalance problem between the "source" and "load", reduce the adjusting numbers of the electrode rods, and prolong the service life of the regenerative electric boilers.

\subsection{Case Study}

Taking a clean heating demonstration project in the northeast of China as an example, the effects of consuming the curtailed wind under the two models of the regenerative electric boilers and the energy storage coordinating regenerative electric boilers are analyzed (the installed capacity of the wind farm is $200 \mathrm{MW}$ ). The curve of the curtailed wind during the whole heating period at the wind farm is shown in Figure 4, and the sampling time interval is $15 \mathrm{~min}$.

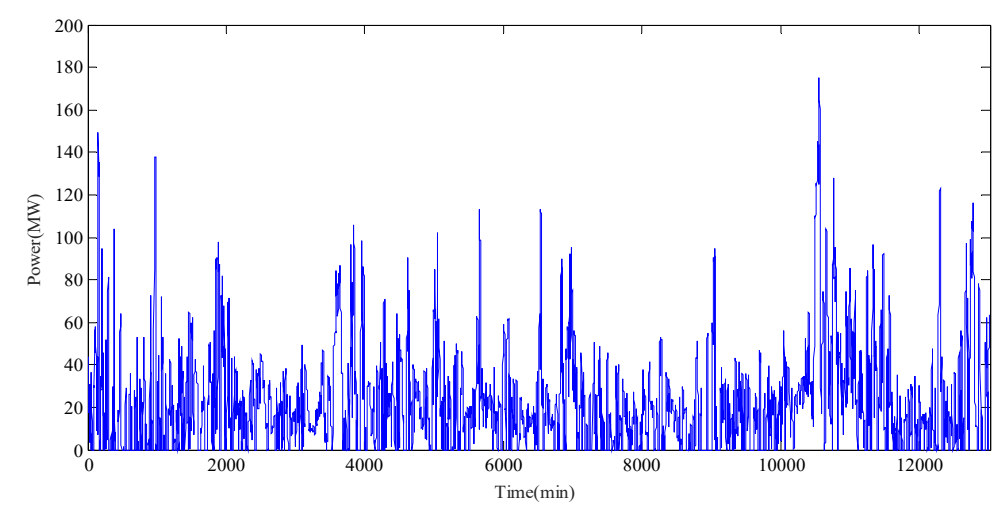

Figure 4. The curve of the curtailed wind during the whole heating period at the wind farm. 


\subsubsection{The Operation of the Regenerative Electric Boilers at Rated Power Mode}

In the heating area, the required minimum daily heating amount $Q_{h o t}$ is equal to $210 \mathrm{MWh}$, and the upper limit of the actual operating power $P_{b o i l}^{\max }$ of the regenerative electric boilers is equal to $30 \mathrm{MW}$. In this case, the regenerative electric boilers only need to operate at constant and full power for $7 \mathrm{~h}$ at the low load and low electricity price. The time of use electricity price in this area is shown in Table 3.

Table 3. The time-of-use electric prices of the large industrial in peak-to-valley periods in this area.

\begin{tabular}{ccc}
\hline Time & Peak-Valley Period & Electric Price (\$) \\
\hline Valley period & $0: 00-5: 00 ; 22: 00-24: 00$ & 0.0457 \\
Flat period & $05: 00-7: 30 ; 11: 00-17: 00 ; 21: 00-22: 00$ & 0.0913 \\
Peak period & $7: 30-11: 30 ; 17: 00-21: 00$ & 0.1370 \\
\hline
\end{tabular}

It can be seen from Table 3 that the operating time of the regenerative electric boilers is set to between 22:00 and 5:00 with a daily low electricity price, it can reduce the electricity cost. Through the pretreatment and analysis of the operating data of the regenerative electric boilers, the maximum ramp-up rate is equal to $60 \mathrm{MW} / \mathrm{h}$, the data of the curtailed wind under three typical heating days in the winter are selected, and the operating power of the regenerative electric boilers is shown in Figure $5 \mathrm{a}$.
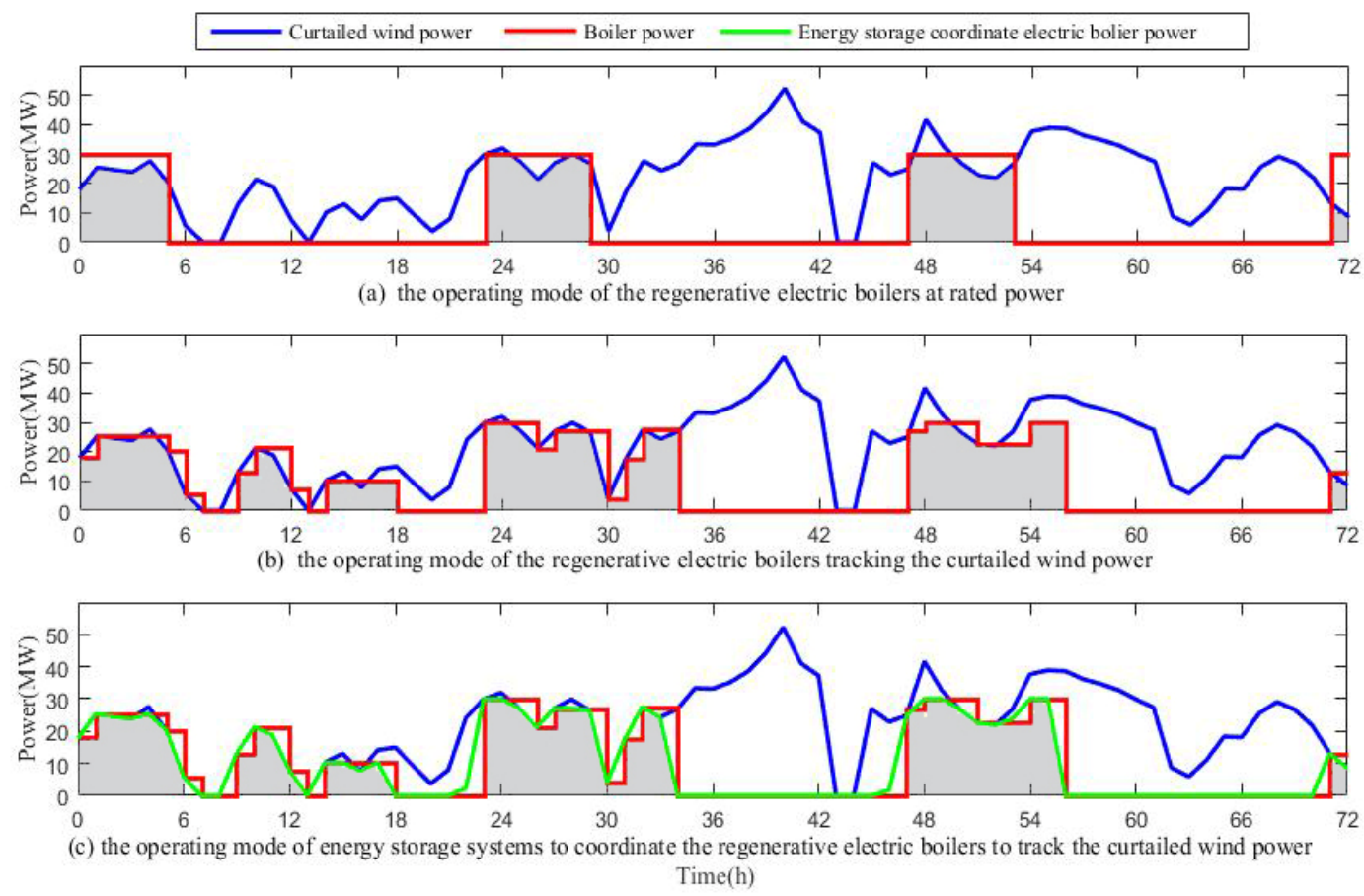

Figure 5. The operating curve of the regenerative electric boilers to consume the curtailed wind under three modes; (a) The operating curve of the regenerative electric boilers at rated power; (b) The operating curve of the regenerative electric boilers tracking the curtailed wind power; (c) The operating power of energy storage systems to coordinate the regenerative electric boilers to track the curtailed wind power.

\subsubsection{The Operation Mode of the Regenerative Electric Boilers Tracking the Curtailed Wind}

Although the start-stop control of the regenerative electric boilers in a fixed time is simple, the space for the curtailed wind still needs to be improved. Consequently, the regenerative electric boilers can be used to track the curtailed wind. Since the operation of the regenerative electric boilers requires the use of mechanical electrode rods, the electrode rods cannot be adjusted frequently in order to avoid excessive mechanical wear, which will shorten the service life. Thus, the adjusting time 
interval of the regenerative electric boilers takes one hour. Due to the great uncertainty of the wind power itself, when the curtailed wind is less than $5 \mathrm{MW}$, the regenerative electric boilers immediately stop operating to reduce the possible additional power consumption. The data of three typical days the same as Section 2.3.1 are selected, and the simulation results are shown in Figure 5b.

2.3.3. The Operation Mode of Energy Storage Systems to Coordinate the Regenerative Electric Boilers to Track the Curtailed Wind

As the regulating speed, depth, and frequency of the regenerative electric boilers cannot match the rapid fluctuations and randomness of wind power, energy storage system is adopted to coordinate the regenerative electric boilers to quickly track the changes of the curtailed wind. The data of three typical days as same as Section 2.3.1 are selected, and the simulation results are shown in Figure 5c.

It can be seen from Figure 5a that the blue curve represents for the curtailed wind, the red curve for the operating power of the regenerative electricity boilers, and the shaded area represents for the curtailed wind directly consumed by the regenerative electric boilers. According to Equation (6), the total amount of the curtailed wind is equal to 1617.1 MWh within three days, in which the total consumption of the curtailed wind is equal to $448.7820 \mathrm{MWh}$, accounting for $27.75 \%$ of the curtailment wind power.

It can be seen from Figure $5 \mathrm{~b}$ when the regenerative electric boilers track the curtailed wind, the total amount of the curtailed wind is $681.74 \mathrm{MWh}$, accounting for $42.16 \%$ of the original curtailed wind power, which is $14.41 \%$ more than in the fixed-time operation. The regenerative electric boilers can reduce the amount of the curtailed wind under the operating model of the regenerative electric boilers tracking the curtailed wind.

It can be seen from Figure $5 \mathrm{c}$ when the energy storage system is used to coordinate the regenerative electric boilers to track the curtailed wind, the total consumption amount of the curtailed wind is $714.64 \mathrm{MWh}$, accounting for $44.19 \%$ of the original curtailed wind power, which is $16.44 \%$ more than in the fixed-time operation. The regenerative electric boilers can greatly reduce the amount of the curtailed wind under the operating mode of the energy storage system to coordinate the regenerative electric boilers to track the curtailed wind.

The charging and discharging power curve of the energy storage system under the operating mode of the energy storage system to coordinate the regenerative electric boilers to track the curtailed wind is shown in Figure 6.

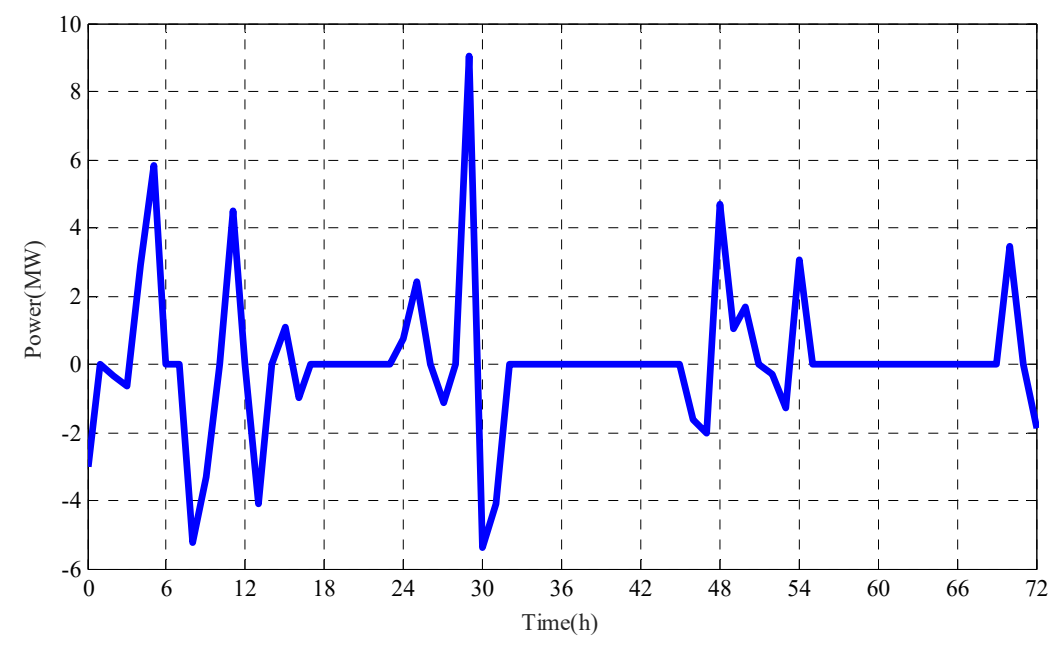

Figure 6. The charging and discharging power curve of the energy storage system.

In order to prevent the energy storage system from over-charging and over-discharging, the range of the SOC of the energy storage system is set at $0.2-0.8$. After the daily operation of the regenerative 
electric boilers, the SOC of the energy storage system will be charged to 0.8 by the remaining curtailed wind power in order to ensure that the energy storage system is fully charged before the next operation. The simulation result shows that the maximum charging power of the energy storage system within three days is $8.76 \mathrm{MW}$. Through the analysis of the typical data during the whole heating period, the maximum charging and discharging power of the energy storage system will not more than $10 \mathrm{MW}$ and less than $6 \mathrm{MW}$ within one day. Taking into account the constraint of the SOC of the energy storage system, the power and capacity of the energy storage system are $10 \mathrm{MW} / 10 \mathrm{MWh}$. The curve of the SOC of the energy storage system during two complete heating periods in three typical days is shown in Figure 7.
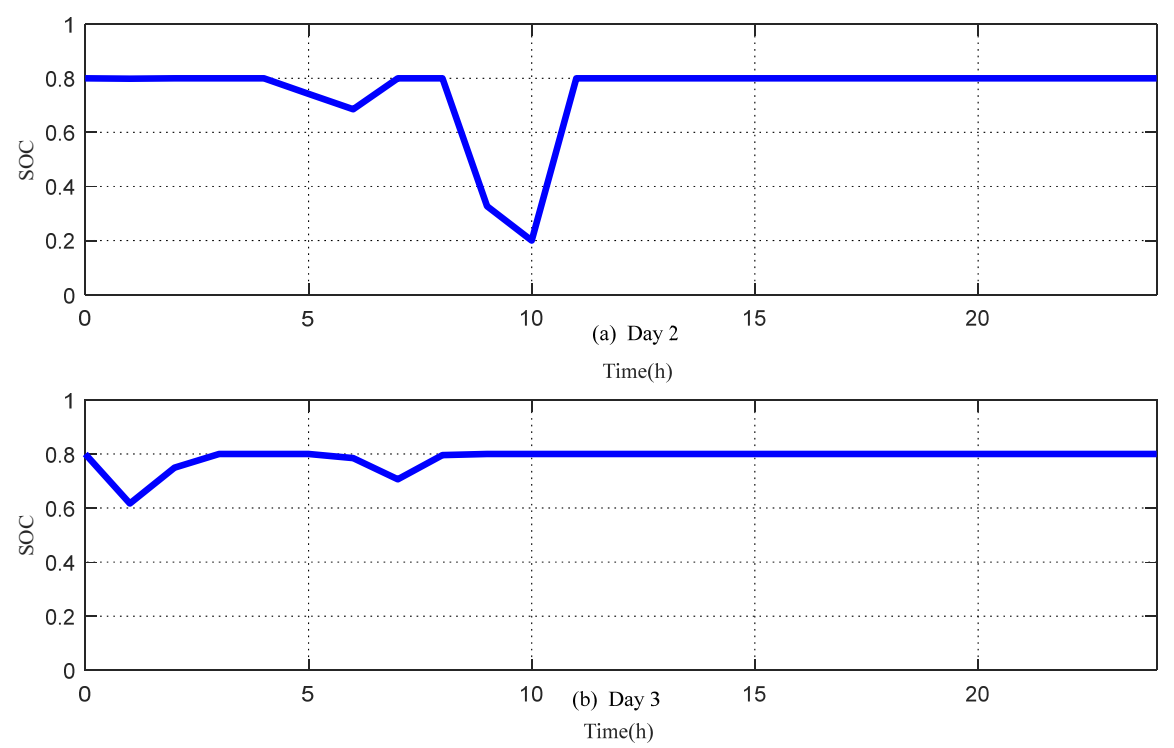

Figure 7. The curve of the SOC of the energy storage system during two complete heating periods in the three typical days. (a) The curve of the SOC of Day 2; (b) The curve of the SOC of Day 3.

It can be seen from Figure 7 that during the two complete heating periods in three typical days, the number of charging and discharging of the energy storage system is only twice, which meets the constraint of charging and discharging times of the energy storage system. At the same time, the configuration of the energy storage system greatly improves the mismatch between the regenerative electric boilers and the curtailed wind. When the number of electrode rods is less regulated, more curtailed wind power can be consumed.

It can be seen from the simulation analysis and comparison of the three operating models that the consumption amount of the curtailed wind using the regenerative electric boilers in a fixed time is relatively low; while the regenerative electric boilers are used to track the curtailed wind, the consumption amount is improved; when the energy storage system is used to coordinate the regenerative electric boilers to track the curtailed wind, the consumption amount is greatly improved.

\section{Economic Evaluation of the Integrated Energy System for the Curtailed Wind Based on Game Theory}

\subsection{Analysis of Game Elements for the Combined System}

Game theory is an important branch of modern mathematics, it has a very wide range of applications in other fields such as society, military and engineering [25,26], its essence belongs to the category of economics. The main application of game theory is that when there are conflicts or interests between two or more decision-making entities, the information held by each decision-making body is different from its own ability. It is a theory how to choose the best policy-making individuals themselves or groups of decision makers according to their respective abilities. Game theory can 
be divided into cooperative games and non-cooperative games according to whether each game participant has the binding force. The cooperative game is mainly applied to a kind of mathematical model to solve the problem of the benefit distribution among various stakeholders. Throughout the game, each participant's decision-making will affect the final result, but when multiple participants coordinate the unified decision-making, it can bring better results, and such a coordinated and unified behavior is called cooperation. Non-cooperative game refers to the framework of non-cooperation in the strategic environment, all the actions of the people as individual actions. It focuses primarily on one's autonomous decision-making independent of the rest of the population in this strategic environment. If there are multiple decision-makers co-existing to pursue their own goals in a decision situation, it is called a game. A game consists of multiple elements, in which the game participants, the participant strategy, the equilibrium and return function are essential elements of the game theory analysis modeling.

Definition 1. The subset $S \subset N$ of any non-null player set $N=\{1,2,3, \ldots, n\}$ is called a coalition, and the total of entire coalitions is indicated as $P(N)$.

Definition 2. In case the players in coalition S form a coalition, no matter what strategy players beyond S apply, the coalition $S$ guarantees to achieve the maximum earnings through coordinating the strategies of its members; the $v(S)$ is called the characteristic function of $n$ persons.

Definition 3. Assume $S$ and $T$ are two coalitions without intersections, the effect of their union at least equals to the sum of the effect of their single operations; it can be described as follows:

$$
v(S \cup T) \geq v(S)+v(T), S \cap T=\varnothing
$$

In order to improve the consumption of the curtailed wind and gain the maximum net incomes of the combined heating system, the cooperative game model is built as follows:

Game Participants:

$B_{b}:\{$ wind power-regenerative electric boilers $\}$

$B_{e}:\{$ wind power-energy storage system\}

Thus, the cooperative game is expressed as:

$$
\{N, v(S), S \subseteq N\}, N=\left\{B_{b}, B_{e},\left(B_{b} \cup B_{e}\right)\right\}
$$

where $B_{b} \cup B_{e}$ is the cooperation between the \{wind power-regenerative electric boilers\} and the \{wind power-energy storage system\}.

$N$ contains three elements, which means three participation models in the game model:

(1) Regenerative electric boilers independently consume the curtailed power of a wind farm $\left(B_{b}\right)$;

(2) Energy storage system independently consume the curtailed power of a wind farm $\left(B_{e}\right)$; and

(3) Regenerative electric boilers and energy storage system jointly consume the curtailed power of a wind farm $\left(B_{b} \cup B_{e}\right)$.

Regenerative electric boilers and energy storage system can consume the curtailed power of a wind farm. Thus, the economics of the combined heating system model (3) must be higher than that of model (1) or model (2), so:

(a) The super-additive works, that is:

$$
v(s)=v\left(\left(B_{b} \cup B_{e}\right)\right) \geq v\left(B_{b}\right)+v\left(B_{e}\right)
$$


(b) Among the three models of (1), (2), and (3), model (3) achieves the highest efficiency, that is, the cooperation between the \{wind power-regenerative electric boilers\} and the \{wind power-energy storage system\} reaches the highest efficiency.

Participant strategy: In the game, the strategies are the curtailed wind of a wind farm at each moment $P_{w}(t)$, the excess curtailed wind power of a wind farm at each moment $P_{r w}$, the operation power of the energy storage system at each moment $P_{e}(t)$, and the heating power of regenerative electric boilers at each moment $P_{b}(t)$. Among them, the variables take continuous values in the allowable range and, thus, constitute a continuous space, marked by $P_{B b}(t)$ and $P_{B e}(t)$. The specific formula is as follows:

$$
\begin{aligned}
P_{w}(t) & =P_{r w}(t)+P_{e}(t)+P_{b}(t) \\
P_{e}(t) & \in\left\{P_{B e}=\left[P_{e}^{\min }, P_{e}^{\max }\right]\right\} \\
P_{b}(t) & \in\left\{P_{B b}=\left[P_{b}^{\min }, P_{b}^{\max }\right]\right\}
\end{aligned}
$$

where $P_{e}^{\max }, P_{e}^{\min }$ are, respectively, the upper and lower limits of the charging and discharging power of the energy storage system with the capacity range from 0 to $1 \mathrm{MWh} ; P_{b}^{\max }, P_{b}^{\min }$ are, respectively, the upper and lower limits of the heating power of the regenerative electric boilers, with the capacity range from 0 to $30 \mathrm{MW}$.

Revenue function:

$$
W=I-C
$$

where I refers to the revenue of the combined heating system; $C$ refers to the cost of the combined heating system, the components contained by I and C are elaborated in Sections 3.2 and 3.3. The cooperative game model has an optimal solution. Under the optimal solution, the value of $\left(P_{r w}^{*}, P_{b}^{*}, P_{e}^{*}\right)$ should meet the following formulas:

$$
\begin{gathered}
P_{w}^{*}(t)=P_{r w}^{*}(t)+P_{e}^{*}(t)+P_{b}^{*}(t) \\
\left(P_{e}^{*}(t), P_{b}^{*}(t)\right)=\operatorname{argmax} W\left(P_{e}^{*}(t), P_{b}^{*}(t)\right)
\end{gathered}
$$

\subsection{Modeling Player Revenues}

The benefits of the combined heating supply system mainly include the revenue of the wind farm connected to the grid $I_{1}$, the income from the system to the heating supply station $I_{2}$, the income which the energy storage system sells the electricity to the grid in the daytime $I_{3}$ and the coal-saving benefits obtained by consuming the curtailed wind $I_{4}$, and all of them are converted to the equivalent daily value:

$$
I=I_{1}+I_{2}+I_{3}+I_{4}
$$

The revenue of the wind farm connected to the grid $I_{1}$ is calculated by Equation (20):

$$
I_{1}=Q_{w} e_{c}
$$

where $Q_{w}$ is the electricity of wind power connected to the grid a day; $e_{\mathcal{c}}$ is the electricity price of the wind power connected to the grid.

The electricity of the wind power connected to the grid a day $Q_{w}$ is calculated by Equation (21)

$$
Q_{w}=\int_{t=0}^{24} \min \left\{P_{b}(t), P_{w}(t)\right\} d t
$$

where $P_{w}(t)$ is the curtailed wind at moment $t$.

The income from the system to the heating supply station $I_{2}$ is calculated by Equation (22):

$$
I_{2}=Q_{n} e_{r}
$$


where $Q_{n}$ is the sold heating from the system to the heating supply station a day (GJ); $e_{r}$ is the price of the sold heating from the system to the heating supply station (\$/GJ).

When the income $I_{3}$ is calculated according to Equation (24), it is necessary to consider the electricity price in different periods, called the "time of use electricity price". The time of use electricity price in peak-valley periods is an effective way of the demand response and its ultimate goal is to increase the benefits of the combined heating system through the peak-shifting and valley-filling $[27,28]$. Before using the time of use electricity price, assume that a single electricity price $e_{0}$ is implemented. After using the time of use price, the prices in peak, flat and valley periods based on the single price are floated to a certain proportion up and down, it can be described as Equation (23):

$$
\begin{cases}e_{p}=e_{0}(1+\alpha), & t \in T_{p} \\ e_{f}=e_{0}(1+\beta), & t \in T_{f} \\ e_{v}=e_{0}(1+\gamma), & t \in T_{v}\end{cases}
$$

where $\alpha, \beta, \gamma$ are, respectively, the floating ranges in peak, flat, and valley periods up and down; $T_{p}, T_{f}, T_{v}$ are, respectively, the time in peak, flat, and valley periods; $e_{p}, e_{f}, e_{v}$ is the time of use electric price in the peak, flat, and valley periods.

Thus, the income $I_{3}$ sold to the grid by the energy storage system in the daytime is calculated by Equation (24):

$$
I_{3}=E_{e} \times\left(S O C_{\max }-S O C_{\min }\right) \times e_{p}
$$

where $E_{e}$ is the rated capacity of the energy storage system $(\mathrm{kWh})$; and $S O C_{\min }, S O C_{\max }$ are the lower and upper limits of the state of charge.

For a cogeneration unit, when the amount of consuming the curtailed wind is $E_{W}$, the savings in coal consumption can be approximated as:

$$
F=\frac{3600 \times \beta_{E B} \times\left(1+\gamma_{C H P}\right)}{29308 \times \beta_{C H P} \times\left(\beta_{E B}+\gamma_{C H P}\right)} E_{W}
$$

where 29,308 is the low calorific value of the standard coal $(\mathrm{kJ} / \mathrm{kg}) ; \beta_{E B}$ is the energy conversion efficiency of electric boilers; $\gamma_{C H P}$ is the ratio of thermoelectricity at the time of curtailing the wind; and $\beta_{C H P}$ is the fuel utilization of thermoelectric units. Since $\beta_{E B}$ is close to 1, Equation (25) can be simplified as:

$$
F=0.123 \frac{\beta_{E B} E_{W}}{\beta_{C H P}}
$$

where the efficiency of electric boilers $\beta_{E B}$ is 0.99 and $\beta_{C H P}$ is 0.7 [28].

Coal-saving benefits obtained by consuming the curtailed wind:

$$
I_{4}=F \times(\lambda+v)
$$

where $\lambda$ is the transaction price of coal, which is $\$ 76.923 /$ ton [29]; $v$ is the income of the emission reduction ( $\$ /$ ton), it can be calculated by Equation (28):

$$
v=x_{1} \times z_{1}+x_{2} \times z_{2}+x_{3} \times z_{3}+x_{4} \times z_{4}
$$

where $x_{1}-x_{4}$ represent the quality of $\mathrm{CO}_{2}, \mathrm{SO}_{2}, \mathrm{NO}_{x}$, and $\mathrm{CO}$ emitted by coal combustion per ton (ton), corresponding to the standard coal of $2600,8,7.5,65 \mathrm{~kg} / \mathrm{ton} ; z_{1}-z_{4}$ represent for the corresponding emission price for the above emission, respectively, are 0.0114, 0.923, 1.231, $10(\$ / \mathrm{kg})[30]$.

\subsection{Costs of the Player}

The costs of the combined heating system mainly include the investment cost of regenerative electric boilers $C_{1}$, the operation and maintenance cost of regenerative electric boilers $C_{2}$, the purchase 
electricity cost of regenerative electric boilers from the grid a day $C_{3}$, the investment and operation and maintenance cost of the energy storage system $C_{4}$, and the daily electricity cost of the energy storage system $C_{5}$. Here the cost is converted to the daily value:

$$
\begin{gathered}
C=C_{1}+C_{2}+C_{3}+C_{4}+C_{5} \\
C_{1}=C_{b} /\left(D_{y} \times N_{b}\right)
\end{gathered}
$$

where $C_{b}$ is the primary investment cost of the regenerative electric boilers (\$); $D_{y}$ is the heating days per year; $N_{b}$ is the average service life of the regenerative electric boilers (year).

The operation and maintenance cost of regenerative electric boilers $C_{2}$ is calculated by Equation (30):

$$
C_{2}=c_{b a r} N
$$

where $c_{b a r}$ is the penalty cost the power adjusting of regenerative electric boilers once (\$); and $N$ is the power adjusting number of the regenerative electric boilers in one day.

When the cost of the purchase electricity $C_{3}$ is calculated (described as Equation (31)), it is necessary to consider the electric price in different time and the consumed electricity in the peak and valley periods:

$$
C_{3}=Q_{p} e_{p}+Q_{f} e_{f}+Q_{v} e_{v}
$$

where $Q_{p}, Q_{f}, Q_{v}$ is the consumption electricity of the regenerative electric boilers in the peak, flat, and valley periods per day $(\mathrm{kWh})$.

The investment and operation and maintenance cost of the energy storage system $C_{4}$ is calculated by Equation (32):

$$
C_{4}=\left(C_{e} P_{e}+C_{E} E_{e}\right) /\left(365 * N_{e}\right)
$$

where $C_{e}, C_{E}$ are, respectively, the unit power cost and unit capacity cost of the energy storage system $(\$ / \mathrm{kW}, \$ / \mathrm{kWh}) ; P_{e}, E_{e}$ are, respectively, the maximum charging and discharging power and rated capacity of the energy storage system $(\mathrm{kW}, \mathrm{kWh}) ; N_{e}$ is the service life of the energy storage system (year).

The daily electricity cost of the energy storage system $C_{5}$ is calculated by Equation (33), considering the valley electricity price:

$$
C_{5}=E_{e} \times\left(S O C_{\max }-S O C_{\min }\right) \times e_{v}
$$

Thus, the overall revenue of the combined heating system $W$ is given in Equation (32):

$$
W=I-C=\left(I_{1}+I_{2}+I_{3}+I_{4}\right)-\left(C_{1}+C_{2}+C_{3}+C_{4}+C_{5}\right)
$$

\subsection{Balance Strategy}

Energy storage systems and regenerative electric boilers are selected as the two types of wind power heating system participants to consume the curtailed wind. The economy of the wind power heating system under the three cooperation modes of "wind power-energy storage system", "wind power-regenerative electric boilers", "wind power-energy storage system-regenerative electric boilers" is evaluated in order to seek the most economical way to consume the curtailed wind. The economic analysis is conducted respectively under three game conditions. To make things simpler, we assume that all the information at the game stage is open and all the game players are totally rational.

\subsection{Constraints of the Model}

The operating power of the regenerative electric boilers must meet the following constraints:

$$
P_{b}^{\min } \leq P_{b}(t) \leq P_{b}^{\max }
$$


where $P_{b}^{\min }, P_{b}^{\max }$ are, respectively, the lower and upper limits of the operating power for the regenerative electric boilers.

The capacity of the regenerative tanks must satisfy Equation (34):

$$
\begin{gathered}
Q_{r}(t)=\int_{0}^{t}\left(P_{b}(t) \times \varepsilon \times 3.6-P_{n}(t)\right) d t \\
Q_{r}^{\min } \leq Q_{r}(t) \leq Q_{r}^{\max }
\end{gathered}
$$

where $\varepsilon$ is the conversion efficiency of the regenerative electric boiler; $P_{n}(t)$ is the lowest heat load requirements at the moment $t(\mathrm{GJ} / \mathrm{h}) ; Q_{r}^{\min }, Q_{r}^{\max }$ are the lower and upper limits of the capacity of the regenerative tanks $(\mathrm{GJ})$.

The required minimum heating load unit at the moment $t$ should satisfy the following constrains:

$$
P_{n}(t)=w(t) \times P_{n b}
$$

where $w(t)$ is the lowest heat load factor at the moment $t ; P_{n b}$ is the basic minimum unit heat load requirements $(\mathrm{GJ} / \mathrm{h})$.

The producing heat of the regenerative electric boilers $Q_{\text {hot }}$ in a day should satisfy the following constraints:

$$
\begin{gathered}
Q_{h o t}=3.6 \times \int_{0}^{24} P_{b}(t) d t \times \varepsilon \\
Q_{h o t} \geq Q_{n}
\end{gathered}
$$

where $Q_{n}$ is the daily minimum heating load value for the heating area.

The energy storage system needs to meet the charging and discharging constraints and the constraints of the SOC as shown in Equation (8).

\subsection{Solution of the Model}

PSO is a global optimization algorithm jointly proposed by social psychologist Eberhart and electrical engineer Kennedy in 1995 [31], which is widely used for the simpler calculation formula, no gradient information and fewer parameters to be adjusted by itself, as well as easier simulation. The basic idea of the PSO algorithm is inspired by the foraging behavior of many birds. Compared with other intelligent optimization algorithms, the PSO algorithm is a kind of simulation of social behavior. The flow chart of the PSO algorithm is shown in Figure 8.

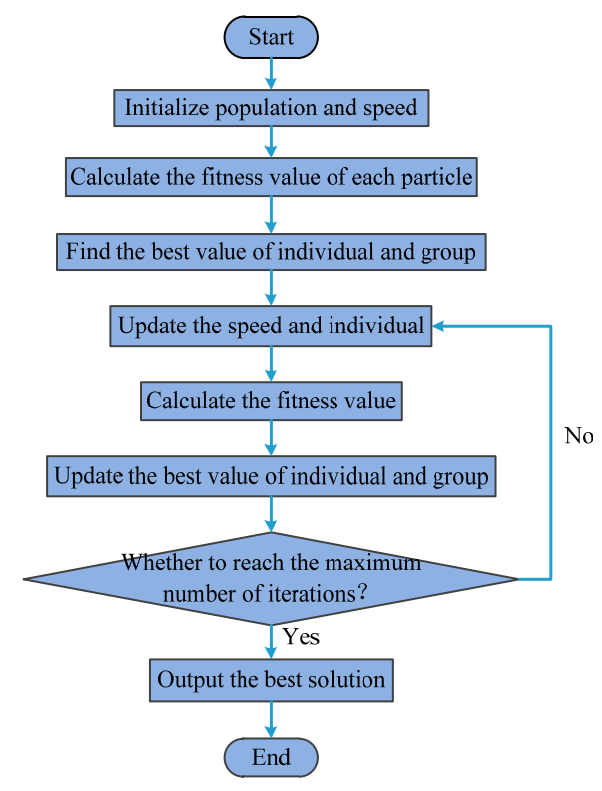

Figure 8. The flow chart of the PSO algorithm. 


\section{Case Study}

\subsection{Parameter Setting of the Model}

Taking a practical demonstration project of the regenerative electric boiler heating in a certain area of China as an example, the installed capacity of the wind farm is $200 \mathrm{MW}$ and the sampling time interval of the wind power takes $15 \mathrm{~min}$. The capacity of a single regenerative electric boiler is $10 \mathrm{MW}$, and three regenerative electric boilers are adopted with a total of $30 \mathrm{MW}$, the purchase cost of $\$ 0.46$ million. Titanium acid batteries are selected as the energy storage system with the capacity of $1 \mathrm{MW} / 0.5 \mathrm{MWh}$, the purchase cost of $\$ 0.69$ million. The power adjustment interval of the regenerative electric boilers is $30 \mathrm{~min}$. The 24-h typical curve of the curtailed wind from 22:00 to the next day 22:00 is shown in Figure 9.

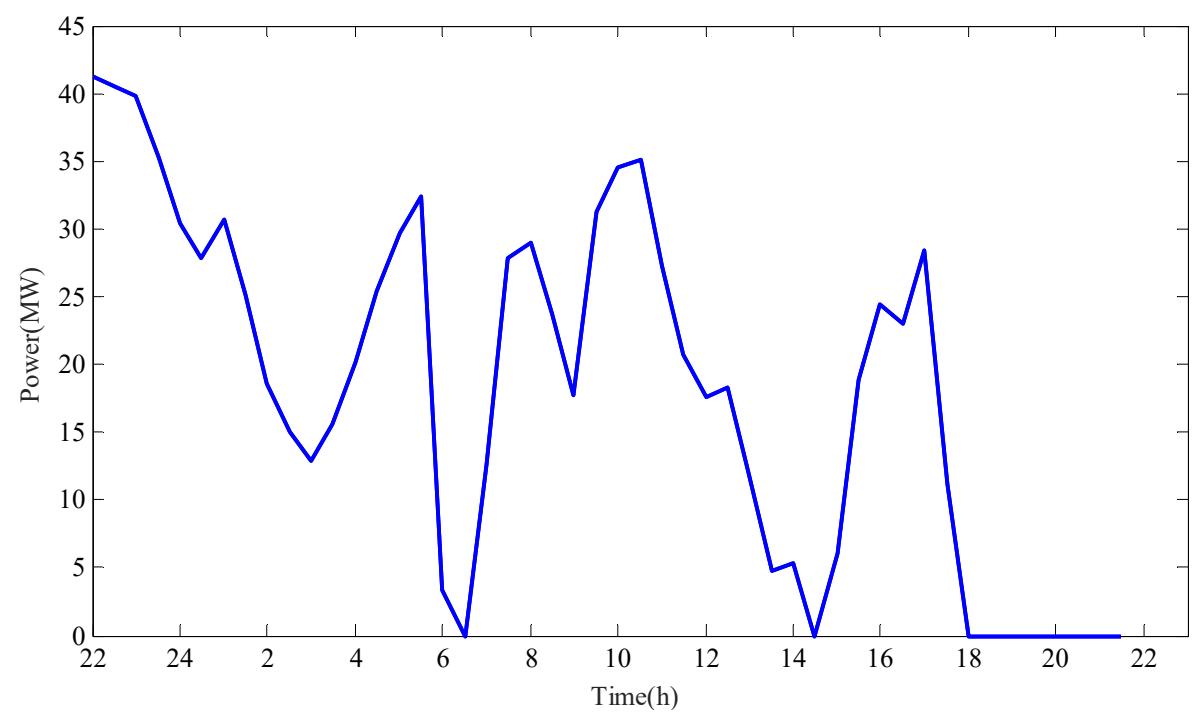

Figure 9. The typical curve of the curtailed wind from 22:00 to the next day 22:00.

According to Equation (6), the total amount of the curtailed wind $E_{w}$ in one day is equal to $436.895 \mathrm{MWh}$, resulting in a great waste of wind resources. The required parameters of the economic evaluation model for the combined heating system are given in Table 4.

Table 4. The required parameters of the economic evaluation model for the combined heating system.

\begin{tabular}{rc}
\hline \multicolumn{1}{c}{ Parameters } & Value \\
\hline The investment costs of regenerative electric boiler $C_{1}$ & $\$ 1.538$ million \\
The average service life of regenerative electric boilers $N_{b}$ & 20 Years \\
The maximum operating power of regenerative electric boilers $P_{b}^{\max }$ & $30 \mathrm{MW}$ \\
The maximum capacity of regenerative tanks $Q_{r}^{\max }$ & $450 \mathrm{GJ}$ \\
The conversion efficiency of regenerative electric boilers $\varepsilon$ & 0.99 \\
The heating days per year $D_{y}$ & $168 \mathrm{Days}$ \\
The price of the sold heat $e_{r}$ & $670 \mathrm{GJ}$ \\
The minimum heating load value for the heating area in one day $Q_{n}$ & $\$ 4 / \mathrm{GJ}$ \\
The electricity price of the wind farm connected to the grid in one day $C_{e}$ & $\$ 0.089 / \mathrm{kWh}$ \\
The power and rated capacity of the energy storage system $P_{e} / E_{e}$ & $1 \mathrm{MW} / 0.5 \mathrm{MWh}$ \\
The investment costs of the energy storage system $C_{4}$ & $\$ 0.692 \mathrm{million}$ \\
The service life of the energy storage system $N_{b y}$ & $15 \mathrm{Years}$ \\
\hline
\end{tabular}

Assuming that the penalty cost of the regenerative electric boilers power adjusted at each time is equal to $\$ 76.92$, the electricity purchase price of the regenerative electric boilers is consistent with 
the price of large industrial electricity prices, that is, $e_{0}=0.091 \$ / \mathrm{KWh}, \alpha=0.5, \beta=0, \gamma=-0.5$. The cost of the purchasing electricity for regenerative electric boilers is larger than the cost of the large industrial electricity. According to Equation (23), the time of use electricity prices of the large industrial electricity in peak-valley periods in this area are given in Table 3.

The required basic minimum unit heating load $P_{n b}=33.65 \mathrm{GJ} / \mathrm{h}$ and the lowest heat load factor is calculated as:

$$
w(t)=\left\{\begin{array}{cl}
0.8 & 0 \leq t \leq 8 \\
0.75 & 8 \leq t \leq 18 \\
1.0 & 18 \leq t \leq 24
\end{array}\right.
$$

The required minimum unit time heating load at each moment is calculated by Equation (36), and the calculated result is shown in Figure 10.

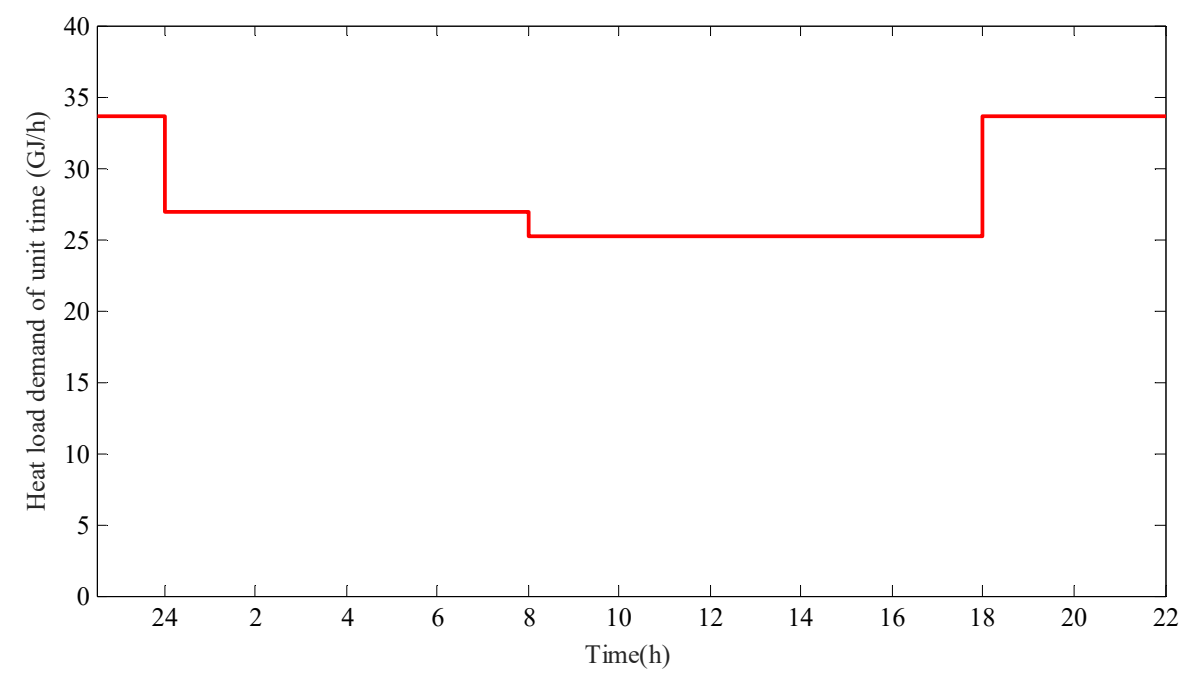

Figure 10. The required minimum unit time heating load.

\subsection{Contrast of Simulation Results}

Mode I: The combination of "wind power and energy storage system" is purely adopted to consume the curtailed wind, the energy storage system will be charged during the valley load periods, that is, during the valley periods of electricity price. The upper and lower limits of SOC are 0.8 and 0.2, respectively. According to Equation (29), the maximum daily income of the combined system is equal to $\$-329.89$, which means a loss of $\$ 329.89$ a day.

Mode II: The combination of "wind power and regenerative electric boilers" is purely used to absorb the curtailed wind by the way of heating for the residents, that is, these parameters including the capacity, investment cost and service life of the energy storage system are equal to 0 . The PSO algorithm is used to solve the model, the population size is 30 , and the number of iterations is 50 . The relationship between the operating power and time of use electricity price of the regenerative electric boilers are shown in Figure 11.

It can be seen from Figure 11 that the operating power of the regenerative electric boilers is higher during the low electric price periods, and lower during the peak electric price periods. This indicates that the lower the purchase cost is, the more electricity will be purchased, which is consistent with the distribution of the curtailed wind. The relationship of the optimal scheduling power of the wind farm and the heat changing of the regenerative tanks is shown in Figure 12. 


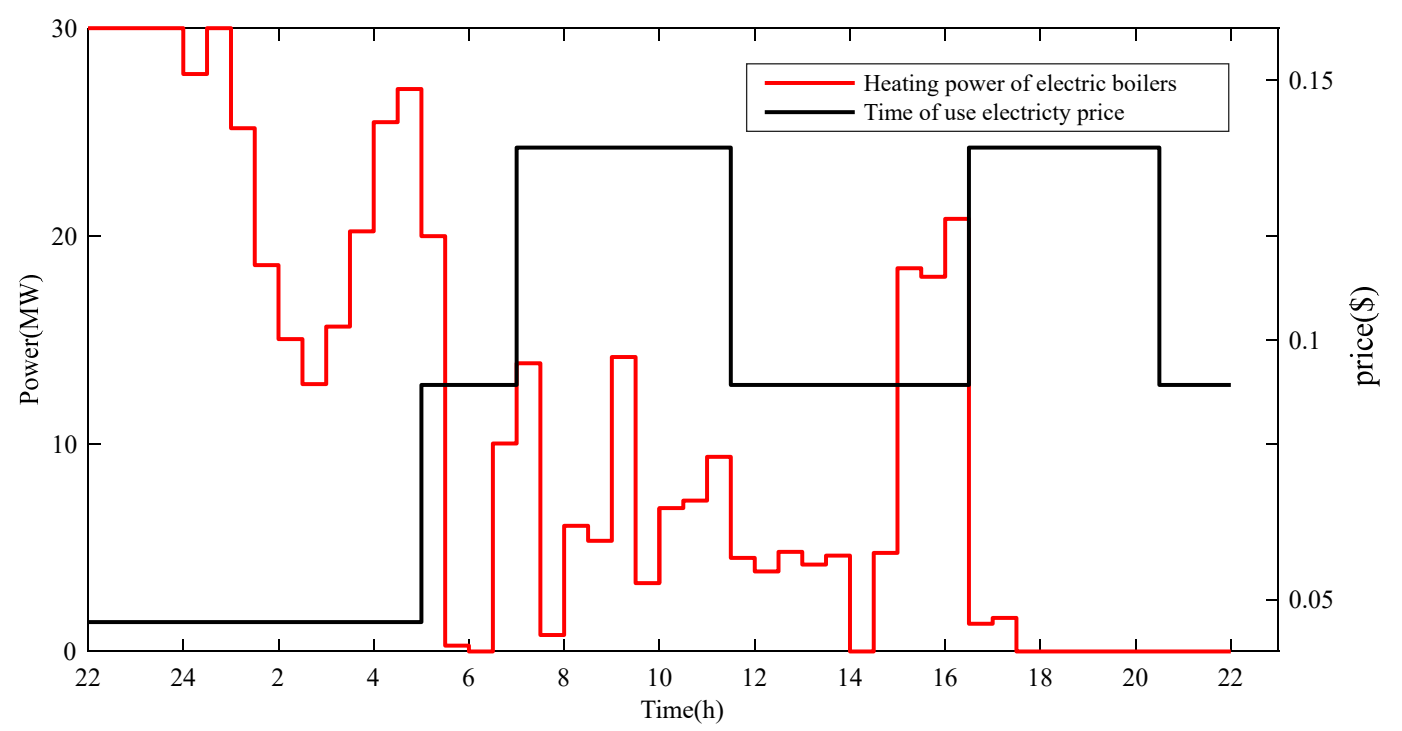

Figure 11. The relationship between the operating power and time of use electricity price of the regenerative electric boilers.

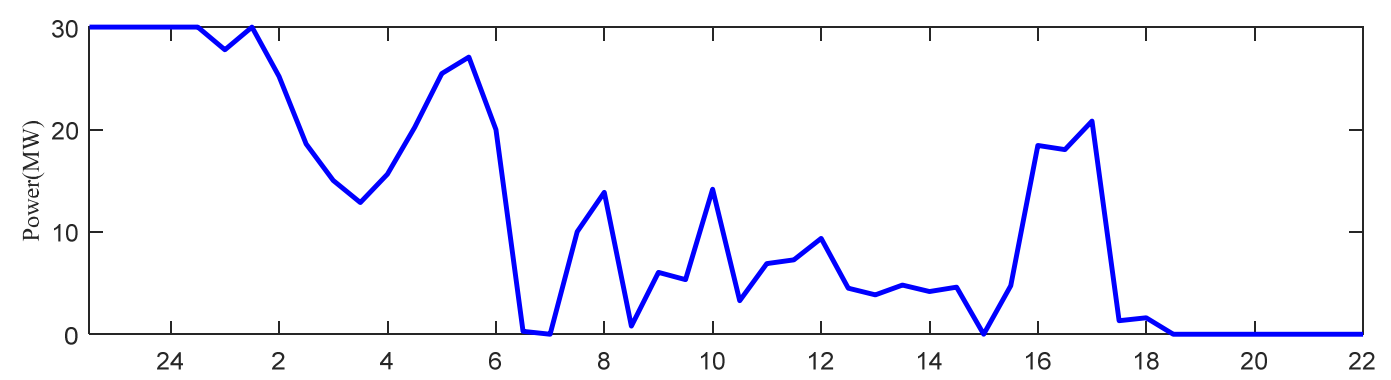

(a) The optomal scheduling power of the wind farm

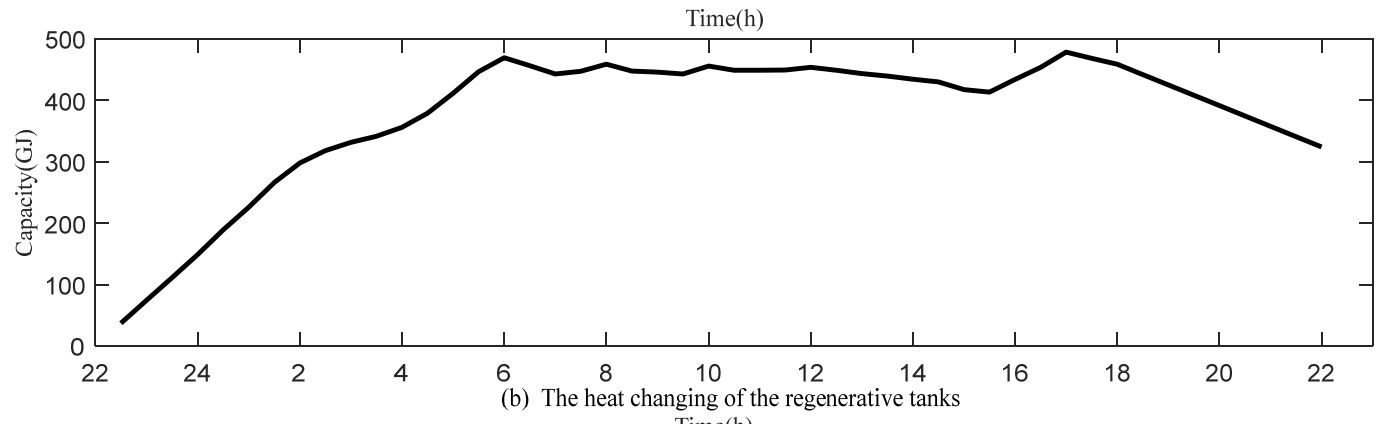

Time(h)

Figure 12. The relationship of the optimal scheduling power of the wind farm and the heat changing of the regenerative tanks; (a) The optimal scheduling power of the wind farm; (b) The heat changing of the regenerative tanks.

It can be seen from Figure 12 that, during the heating period, a large amount of the curtailed have modified it as suggested. Wind was connected to the grid after adding the regenerative electric boilers, especially during the valley load period at night, which indicates that the consumption of the curtailed wind was significantly improved. The heat of the regenerative tanks reached the maximum at 5:00 the next day, then dropped slightly, and was higher at 22:00 of the next day than the first day, which indicates that the amount of the curtailed wind was larger in the heating period. At this point 
the regenerative tanks can store some heat to prepare for the next day when the wind is relatively small so as to avoid additional purchased electricity costs from the grid.

The curves of the wind power output and time-of-use electricity price with the curve before and after adding the regenerative electric boilers are shown in Figure 13.

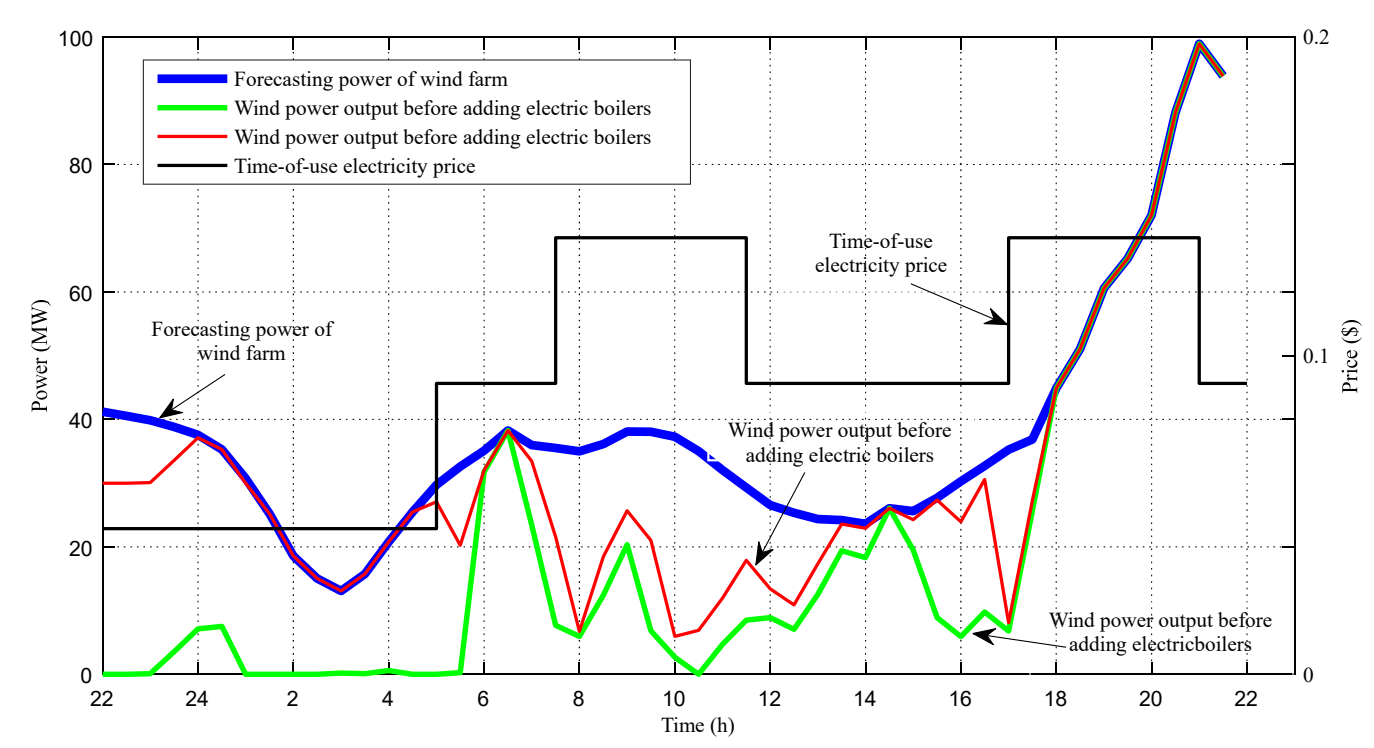

Figure 13. The curve of the wind power output and time-of-use electricity price with the curve before and after adding the regenerative electric boilers.

It can be seen from Figure 13 that the output power of the wind farm increased significantly under Mode II. As the time-of-use electricity price was in the valley load period, the curtailed wind was absorbed as much as possible within the allowable operating power of the regenerative electric boilers. However, when the time-of-use electricity price was in the flat and peak load periods, the consumption amount of the curtailed wind was relatively low. According to Equation (6), the consumption amount of the curtailed wind after adding the regenerative electric boilers is $300.1034 \mathrm{MWh}$, accounting for $68.7 \%$ of the original curtailed wind power. The changing curve of the daily earnings with the number of iterations under Mode II is shown in Figure 14a.

Mode III: The cooperative game mode of "wind power-energy storage system-regenerative electric boilers" is used to absorb the curtailed wind, while realizing the wind power heating for the residents, in which the energy storage system is adopted to decrease the power adjusting frequency of the regenerative electric boilers. In accordance with the provisions of regenerative electric boiler manufacturers, the power regulation interval of regenerative electric boilers is adjusted to not less than half an hour. Before adding the energy storage system, the adjusting number of the regenerative electric boilers is 36 times a day; after adding the energy storage system, the adjusting number is decreased to 32 times a day.

The changing curve of the daily earnings with the number of iterations under Mode II and Mode III is shown in Figure 14.

It can be seen from Figure 14a when the number of iterations reaches 18 times, the daily gain reaches the maximum, and then with the increase of the number of iterations, the daily return does not change, the maximum daily gain is equal to $\$ 10,261.72$.

The similarity was shown in Figure $14 \mathrm{~b}$ when the number of iterations reaches 32 times, the daily gain reaches the maximum, and then the daily return does not change as the number of iterations increases, the maximum daily return is equal to $\$ 11,245.00$. In the cooperative game mode, the operation frequency of the regenerative electric boilers is adjusted 32 times. The operation and maintenance cost of the regenerative electric boilers is reduced and the daily return of the system is 
increased. The simulation results show that the adding of the energy storage system can reduce the adjusting number of regenerative electric boilers and improve its service life.

The SOC curve of the energy storage system under Mode III is shown in Figure 15.
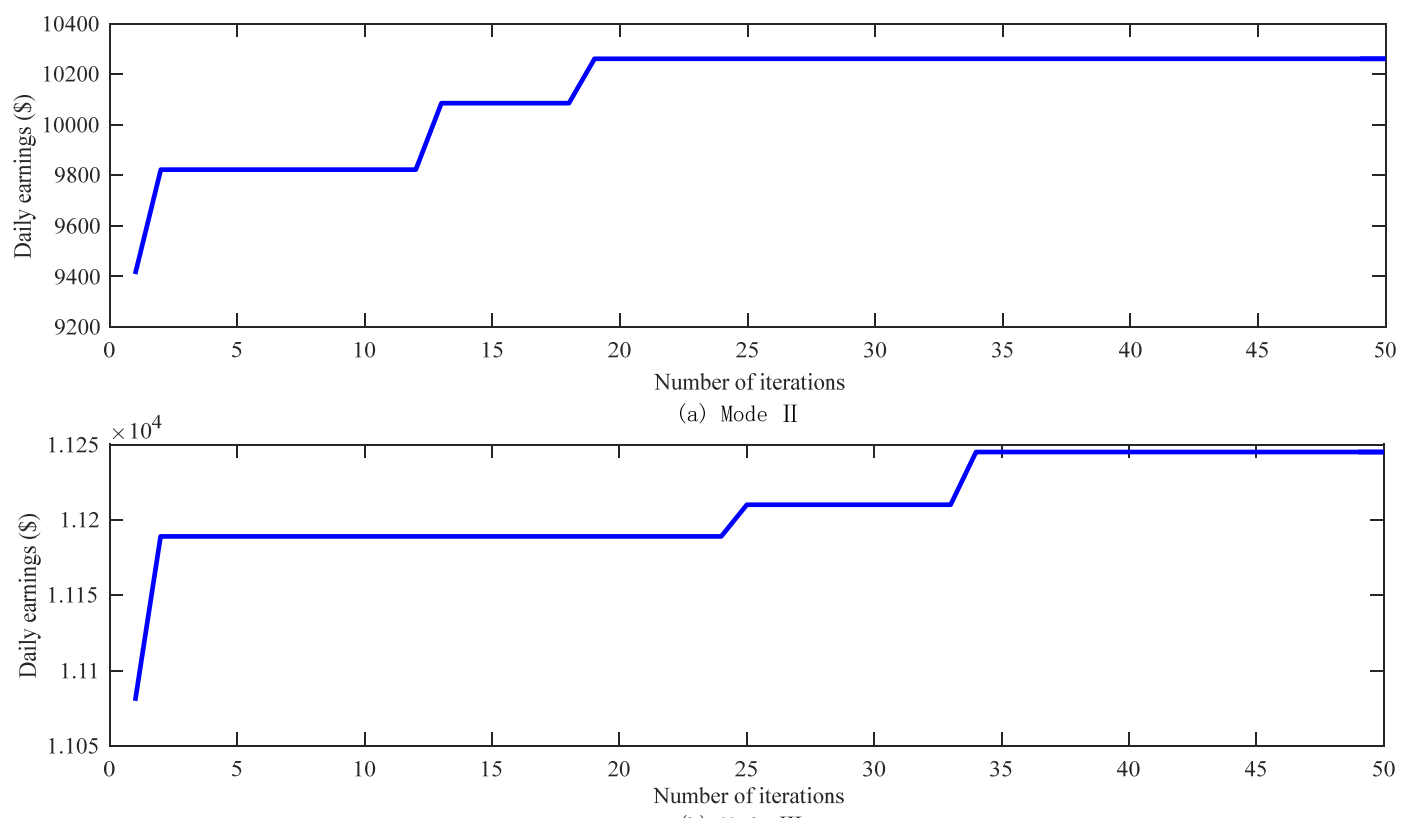

(b) Mode III

Figure 14. The changing curve of the daily earnings with the number of iterations obtained by the PSO optimization algorithm under Mode II and Mode III. (a) The changing curve of the daily earnings obtained by PSO under Mode II; (b) The changing curve of the daily earnings obtained by PSO under Mode III.

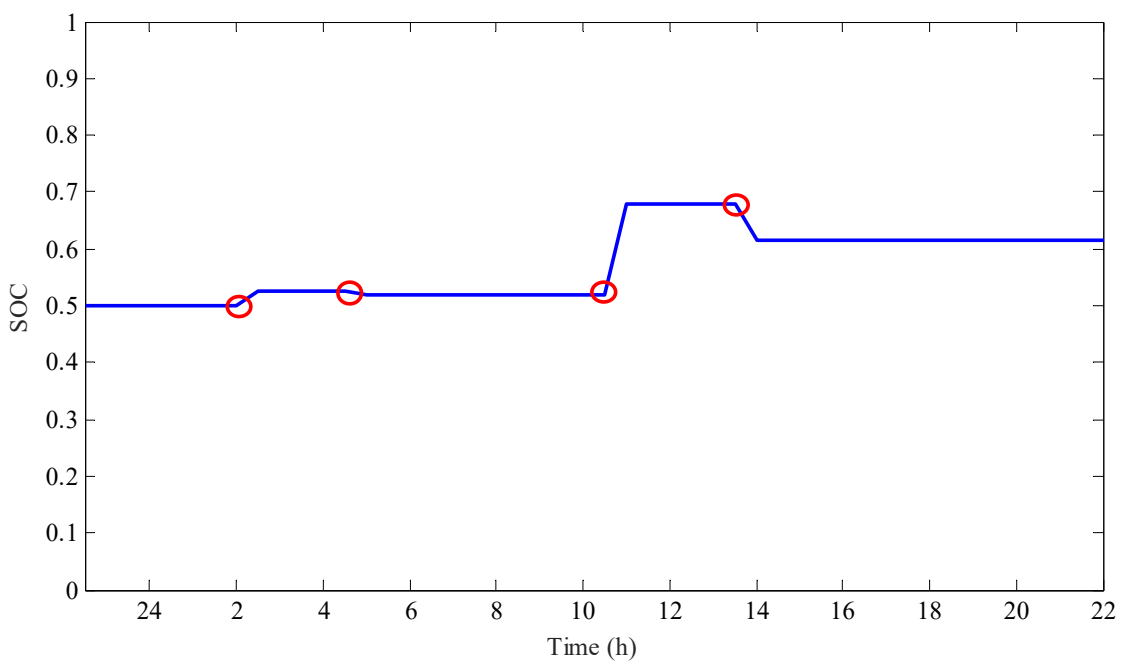

Figure 15. The SOC curve of the energy storage system in the cooperative game mode.

It can be seen from Figure 15 that the SOC of the energy storage system changes four times, at 10:00, 11:00, 14:00, and 17:00, which means that the energy storage system is used to quickly absorb the change of the curtailed wind when the regenerative electric boilers cannot satisfy the rapid fluctuations of the curtailed wind. 


\subsection{Comparison Results of Different Optimization Algorithms}

For comparative analysis, the firefly algorithm (FA) [32] is used to solve the above model compared with the particle swarm optimization algorithm. The FA algorithm is a new meta-heuristic search optimization method that simulates firefly foraging behavior in practice. It has been used in many fields due to being simple, having fewer parameters, ease of implementation, and so on. Here the population size is 30 , and the maximum number of evolutionary iterations is 50 . The FA algorithm is introduced to optimize the models of Mode II and Mode III, respectively, and the maximum daily earnings curve of the combined system obtained by the FA optimization algorithm is shown in Figure 16.
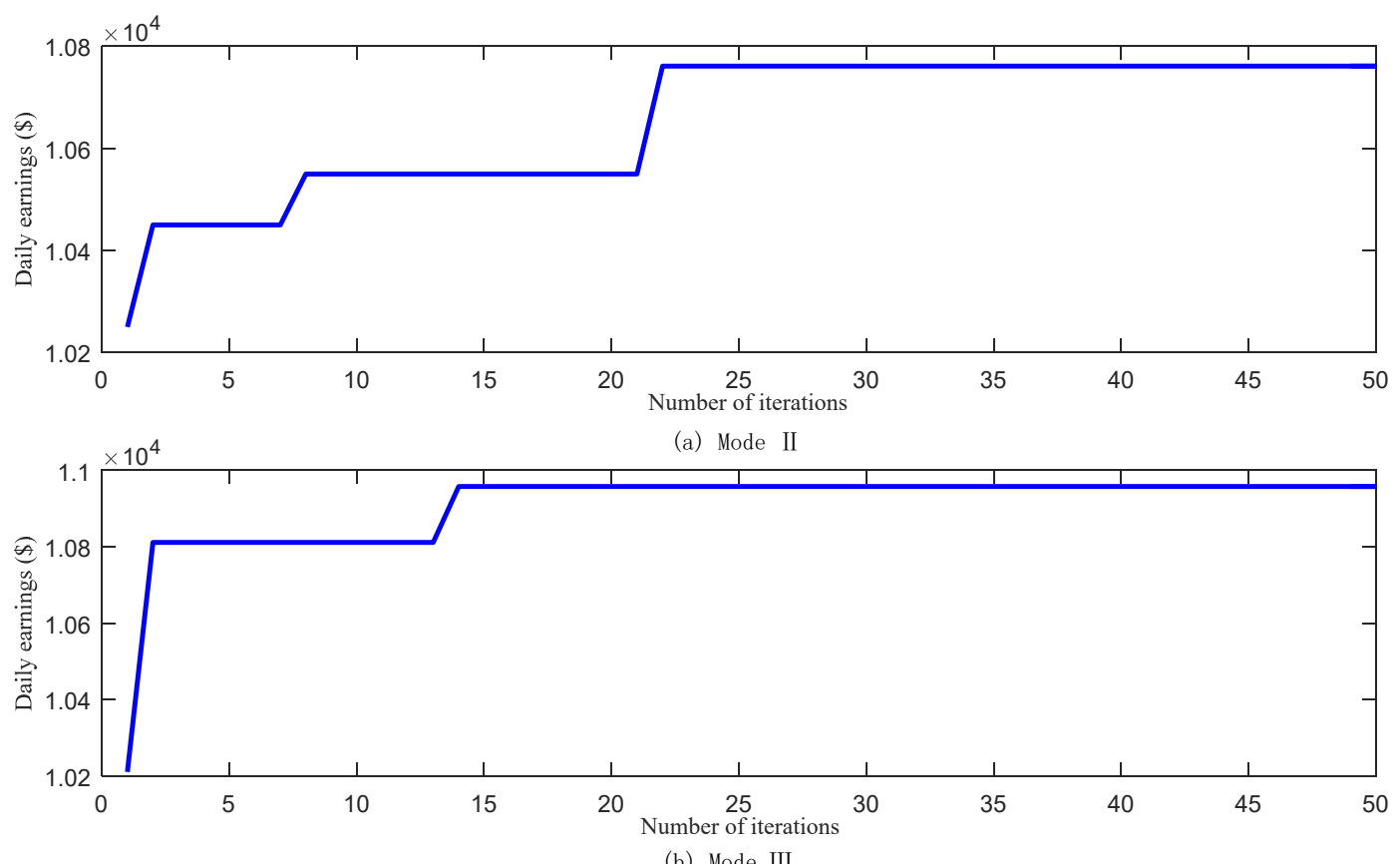

(b) Mode III

Figure 16. The maximum daily earnings iteration curve of the combined system obtained by the FA optimization algorithm under Mode II and Mode III. (a) The daily earnings curve obtained by FA under Mode II; (b) The daily earnings curve obtained by FA under Mode III.

It can be seen from Figure 16, the maximum daily earnings obtained by the FA algorithm are $\$ 10,761.01$ and $\$ 10,957.47$, respectively, which are lower than the results obtained by the PSO algorithm. The optimization results are shown in Table 5.

Table 5. The optimization results obtained by FA and PSO algorithms under different operating modes in a day.

\begin{tabular}{ccccccc}
\hline \multirow{2}{*}{ Operating Mode } & \multicolumn{3}{c}{ PSO Algorithm } & \multicolumn{3}{c}{ FA Algorithm } \\
\cline { 2 - 7 } & Cost (\$) & Revenue (\$) & Net Profit (\$) & Cost (\$) & Revenue (\$) & Net Profit (\$) \\
\hline Mode I & 412.09 & 82.2 & -329.89 & 412.09 & 122.88 & -289.21 \\
Mode II & $25,346.08$ & $35,607.80$ & $10,261.72$ & $23,088.27$ & $33,849.28$ & $10,761.01$ \\
Mode III & $25,758.16$ & $370,003.16$ & $11,245.00$ & $23,707.26$ & $34,664.73$ & $10,957.47$ \\
\hline
\end{tabular}

It can be seen from Table 5 that because the cost of the energy storage equipment is higher (here, the capacity of the energy storage equipment needs $10 \mathrm{MW}$ ), the daily net profit obtained by the PSO algorithm is $\$-329.89$ a day, it is infeasible that the energy storage is used to consume the curtailed wind alone. When the regenerative electric boilers are used to consume the curtailed wind alone (here, the capacity of the regenerative electric boilers equipment need $30 \mathrm{MW}$ ), the daily 
net profit obtained by PSO algorithm is obviously higher than that obtained by the FA algorithm. When the energy storage system is used to coordinate the regenerative electric boilers for an actively consumption of the curtailed wind (here the capacity of the energy storage equipment takes $1 \mathrm{MW}$ and the capacity of the regenerative electric boilers equipment need $30 \mathrm{MW}$ ), the daily net profit obtained by PSO algorithm is obviously higher than that obtained by the FA algorithm.

\section{Conclusions}

Aiming at the problem of the seriously curtailed wind caused by the shortage of peaking capacity during the winter heating periods in a certain area of China, a flexible control method using the integrated energy system to consume the curtailed wind is proposed in this paper, and the economic evaluation model of the integrated energy system for the curtailed wind based on game theory is established. The main conclusions are as follows:

(1) When regenerative electric boilers are used to consume the curtailed wind alone, under the operating condition of the rated power, regenerative electric boilers consume, in total, $448.7820 \mathrm{MWh}$ of curtailed wind within three typical days, accounting for $27.75 \%$ of the original amount; under the operating condition of tracking the curtailed wind, regenerative electric boilers consume, in total, $681.74 \mathrm{MWh}$ of curtailed wind within three typical days, accounting for $42.16 \%$ of the original amount. When the energy storage system is used to coordinate regenerative electric boilers for tracking the curtailed wind, the combination of the energy storage system and regenerative electric boilers totally consumed 714.64 MWh of curtailed wind within three typical days, accounting for $44.19 \%$ of the original amount. Therefore, the addition of energy storage system can increase the proportion of wind power consumption.

(2) Due to the large inertia of the thermal system and the adjustment speed being slow, the inertia of the energy storage system is relatively small and the adjustment speed is fast. Before adding the energy storage system, the adjusting numbers of the regenerative electric boilers is 36 times a day; after adding the energy storage system, the adjusting numbers of the regenerative electric boilers is decreased to 32 times a day. Therefore, the addition of the energy storage system can reduce the adjusting numbers of regenerative electric boilers and improve its service life.

(3) As an important means of the peak shaving, the energy storage system is of great significance to solve the problem of renewable energy connected to the grid. Due to the high investment and maintenance cost of the energy storage system, the energy storage used to consume the curtailed wind cannot generate the revenue alone. With the decrease of the investment cost of the energy storage system and regenerative electric boilers, as well as the support of national policies, the economic benefits of the integrated energy system to consume the curtailed wind will be greatly enhanced, it has a wider application prospect in renewable energy consumption.

Author Contributions: X.H. contributed to the paper topics and writing; F.W. contributed to the simulation and experiment; C.T. helped perform the analysis with constructive discussions; K.X. contributed to the preliminary preparation and data collection; J.Z. helped later revision and improvement of the paper.

Funding: This research was funded by [the National Natural Science Fund Project] grant number [51577065] and [State Grid Corporation Project] grant number [KY-SG-2016-204-JLDKY].

Acknowledgments: This paper is supported by the National Natural Science Fund Project (51577065) and State Grid Corporation Project (KY-SG-2016-204-JLDKY).

Conflicts of Interest: The authors declare no conflict of interest.

\section{Nomenclature}

$P_{w}(t) \quad$ The curtailed wind power at moment $t$

$P_{\text {pre }}(t) \quad$ The forecasting wind power at moment $t$

$P_{S}(t) \quad$ The actual wind power at moment $t$

$P_{b}(t) \quad$ The operating power of the regenerative electric boilers at moment $t$ 


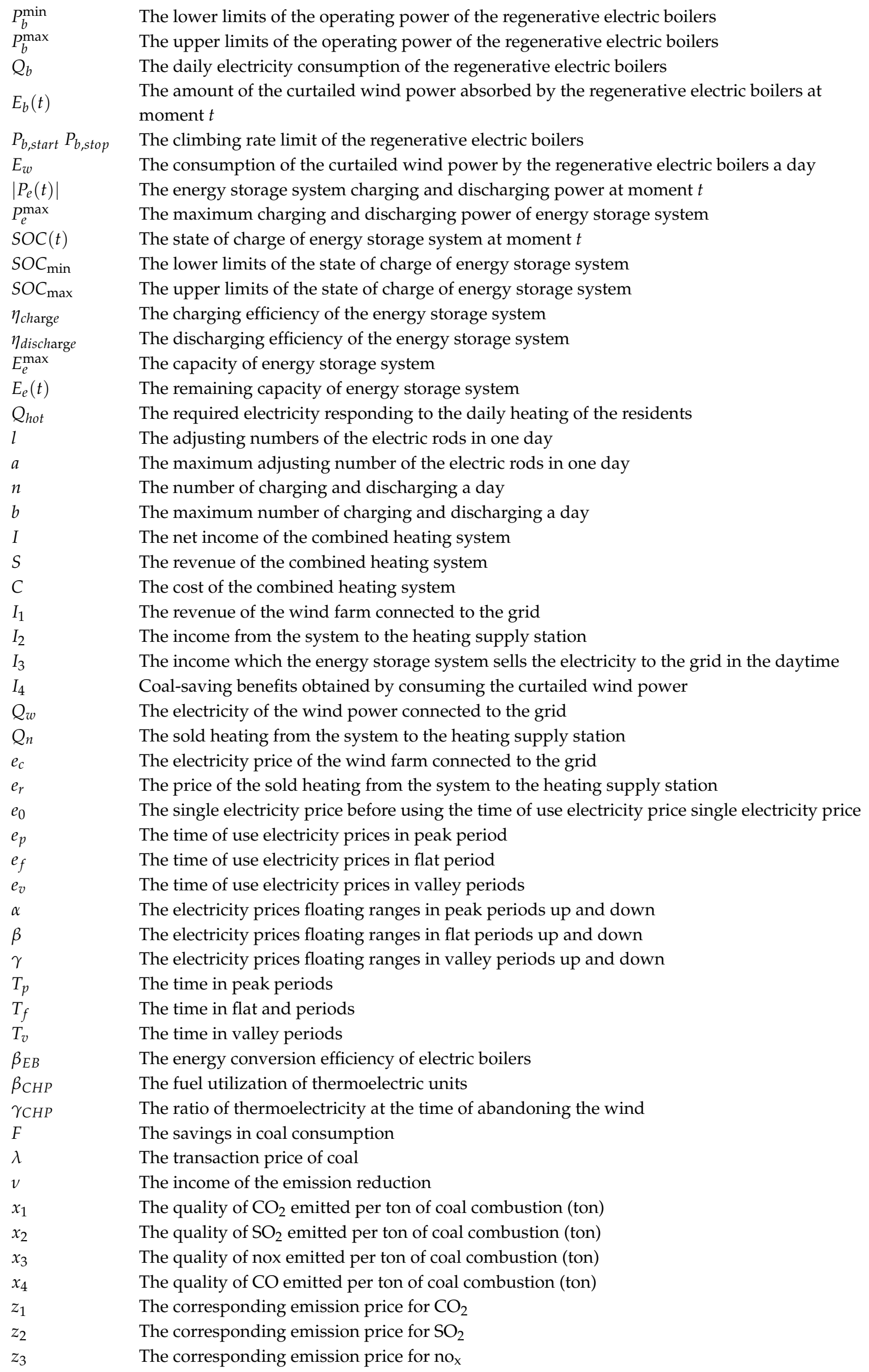


The corresponding emission price for $\mathrm{CO}$

The investment cost of regenerative electric boilers

The operation and maintenance cost of regenerative electric boilers

The purchase electricity cost of regenerative electric boilers from the grid

The investment and operation and maintenance cost of the energy storage system

The daily electricity cost of the energy storage system

The primary investment cost of the regenerative electric boilers

The heating days per year

The average service life of the regenerative electric boilers

The penalty cost the power adjusting of regenerative electric boilers once

The power adjusting frequency of the regenerative electric boilers

The consumption electricity of the regenerative electric boilers in the peak periods

The consumption electricity of the regenerative electric boilers in the flat periods

The consumption electricity of the regenerative electric boilers in the valley periods

The unit power cost of the energy storage system

The unit capacity cost of the energy storage system

The maximum charging and discharging power of the energy storage system

The rated capacity of the energy storage system

The service life of the energy storage system

The capacity of the regenerative tanks

The required minimum heating load unit at the moment $t$

The conversion efficiency of the regenerative electric boiler

The lower limits of the capacity of the regenerative tanks

The upper limits of the capacity of the regenerative tanks

The lowest heat load factor at the moment $t$

The basic minimum unit heat load requirements

\section{References}

1. GWEC. 2016 Global Wind Power Installed Statistics. Wind Energy 2017, 2, 52-57.

2. Rong, S.; Li, Z.; Li, W. Investigation of the Promotion of Wind Power Consumption Using the Thermal-Electric Decoupling Techniques. Energies 2015, 8, 8613-8629. [CrossRef]

3. Zhang, Y. Statistics of Curtailed Winds in China from 2011 to 2015. Wind Energy 2016, 2, 34-35.

4. Liu, B.; He, Z.; Jin, H. Wind Power Status and Development Trends. J. Northeast Dianli Univ. 2016, 36, 7-13. [CrossRef]

5. Xin, R. Analysis and Solution Proposals of Domestic Wind Power Energy Curtailment. Manag. Technol. SME 2017, 8, 149-150.

6. Zhu, L.; Chen, N.; Han, H. Key problems and solutions of wind power accommodation. Autom. Electr. Power Syst. 2011, 35, 29-34.

7. Chen, H.; Zhang, R.; Bai, L.; Jiang, T.; Li, G.; Jia, H.; Li, X. Stochastic Scheduling of Integrated Energy Systems Considering Wind Power and Multienergy Loads Uncertainties. J. Energy Eng. 2017, 143, 1-9. [CrossRef]

8. Jing, Z.X.; Jiang, X.S.; Wu, Q.H.; Tang, W.H.; Hua, B. Modelling and optimal operation of a small-scale integrated energy based district heating and cooling system. Energy 2014, 73, 399-415. [CrossRef]

9. Rong, S.; Li, W.; Li, Z.; Sun, Y.; Zheng, T. Optimal Allocation of Thermal-Electric Decoupling Systems Based on the National Economy by an Improved Conjugate Gradient Method. Energies 2016, 9, 17. [CrossRef]

10. Hozouri, M.A.; Abbaspour, A.; Fotuhi-Firuzabad, M.; Moeini-Aghtaie, M. On the Use of Pumped Storage for Wind Energy Maximization in Transmission-Constrained Power Systems. IEEE Trans. Power Syst. 2015, 30, 1017-1025. [CrossRef]

11. Krajačić, G.; Lončar, D.; Duić, N.; Zeljko, M.; Arántegui, R.L.; Loisel, R.; Raguzin, I. Analysis of financial mec hanisms in support to new pumped hydropower storage projects in Croatia. Appl. Energy 2013, 101, 161-171. [CrossRef]

12. Zhang, S.; Andrews-Speed, P.; Perera, P. The evolving policy regime for pumped storage hydroelectricity in China: A key support for low-carbon energy. Appl. Energy 2015, 150, 15-24. [CrossRef] 
13. Ding, M.; Liu, X.; Xie, J. Research on Heat and Electricity Coordinated Dispatch Model of Multi-area for Improving Wind Power Accomodation Ability. Proc. CSEE 2017, 37, 4079-4088.

14. Li, J.; Hu, L. Research on Accommodation Scheme of Curtailed Wind Power Based on Peak-Shaving Electric Boiler in Secondary Heat Supply Network. Power Syst. Technol. 2015, 39, 3286-3291.

15. Nielsen, M.G.; Morales, J.M.; Zugno, M.; Pedersen, T.E.; Madsen, H. Economic valuation of heat pumps and electric boilers in the Danish energy system. Appl. Energy 2016, 167, 189-200. [CrossRef]

16. Xu, M.; Jiang, D. Energy Efficiency and Economic Analysis of Wind Heating System. Renew. Energy 2015, $37,42-47$.

17. Liu, D.; Zhang, G.; Huang, B.; Liu, W. Optimum Electric Boiler Capacity Configuration in a Regional Power Grid for a Wind Power Accommodation Scenario. Energies 2016, 9, 144. [CrossRef]

18. Huang, J.; Li, Z.; Wu, Q.H. Coordinated dispatch of electric power and district heating networks: A decentralized solution using optimality condition decomposition. Appl. Energy 2017, 206, 1508-1522. [CrossRef]

19. Teleke, S.; Baran, M.E.; Bhattacharya, S.; Huang, A.Q. Optimal Control of Battery Energy Storage for Wind Farm Dispatching. IEEE Trans. Energy Convers. 2010, 25, 787-794. [CrossRef]

20. Wang, H.; Zhuang, G.; Li, G.; Li, D. Optimized Control of Wind Power Consumption Based on Regenerative Electric Bolier and Energy Storage System. Distrib. Energy 2016, 1, 1-7.

21. Che, G. Technology of heat-storage electric heating boiler and its application. East China Electr. Power 2004, 32, 27-29.

22. Quan, L.; Wang, W.; Han, S.; Yuan, S.; Zhang, J.; Li, W. A New Evaluation Method for Wind Power Curtailment Based on Analysis of System Regulation Capability. Power Syst. Technol. 2013, 37, 1887-1894.

23. Han, X.; Ji, T.; Zhao, Z.; Zhang, H. Economic evaluation of batteries planning in energy storage power stations for load shifting. Renew. Energy 2015, 78, 643-647. [CrossRef]

24. Su, H.I.; Gamal, A.E. Modeling and Analysis of the Role of Energy Storage for Renewable Integration: Power Balancing. IEEE Trans. Power Syst. 2013, 28, 4109-4117. [CrossRef]

25. Lu, Q.; Chen, L.; Mei, S. Typical Applications and Prospects of Game Theory in Power System. Proce. CSEE 2014, 34, 5009-5017.

26. Mei, S.; Wang, Y.; Liu, F. A Game Theory Based Planning Model and Analysis for Hybrid Power System with Wind Generators-Photovoltaic Panels-Storage Batteries. Autom. Electr. Power Syst. 2011, 35, $13-19$.

27. Li, Y.; Wang, Z.; Lu, Y. The Implementation of Peak and Valley Time Price for Electricity and the Response of Large Industries. Autom. Electr. Power Syst. 2001, 25, 45-48.

28. Ruan, W.; Wang, B.; Li, Y.; Yang, S. Customer Response Behavior in Time-of-Use Price. Power Syst. Technol. 2012, 36, 86-93.

29. Lu, Q.; Jiang, H.; Chen, T. Wind Power Accommodation by Combined Heat and Power Plant with Electric Boiler and Its National Economic Evaluation. Autom. Electr. Power Syst. 2014, 38, 6-12.

30. Lu, Q.; Liu, Y.; Liu, L. Research on Coal-saving Performance and Optimal Configuration of Wind Power Heating Project Considering Wind Power Curtailment. Proc. CSEE 2017, 37, 4699-4711.

31. Coello, C.A.C.; Pulido, G.T.; Lechuga, M.S. Handling multiple objectives with particle swarm optimization. IEEE Trans. Evol. Comput. 2004, 8, 256-279. [CrossRef]

32. Yang, X.S. Firefly Algorithms for Multimodal Optimization. In International Symposium on Stochastic Algorithms; Springer: Berlin/Heidelberg, Germany, 2009; Volume 5792, pp. 169-178.

(C) 2018 by the authors. Licensee MDPI, Basel, Switzerland. This article is an open access article distributed under the terms and conditions of the Creative Commons Attribution (CC BY) license (http://creativecommons.org/licenses/by/4.0/). 